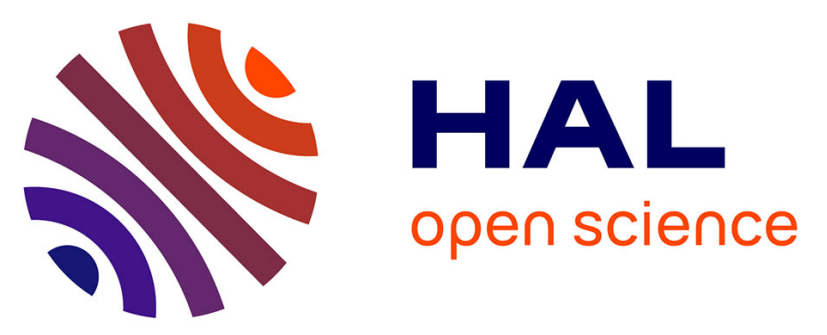

\title{
A novel oxalate-based three dimensional polymorphs supramolecular compounds: Synthesis, spectroscopic characterization, magnetic and photocatalytic properties
}

Rihab Dridi, Saoussen Namouchi Cherni, Farid Fettar, Nassira

Chniba-Boudjada, Mohamed Faouzi Zid

\section{To cite this version:}

Rihab Dridi, Saoussen Namouchi Cherni, Farid Fettar, Nassira Chniba-Boudjada, Mohamed Faouzi Zid. A novel oxalate-based three dimensional polymorphs supramolecular compounds: Synthesis, spectroscopic characterization, magnetic and photocatalytic properties. Journal of Molecular Structure, 2020, 1205, pp.127573. 10.1016/j.molstruc.2019.127573 . hal-03063780

\author{
HAL Id: hal-03063780 \\ https://hal.science/hal-03063780
}

Submitted on 4 Jan 2021

HAL is a multi-disciplinary open access archive for the deposit and dissemination of scientific research documents, whether they are published or not. The documents may come from teaching and research institutions in France or abroad, or from public or private research centers.
L'archive ouverte pluridisciplinaire HAL, est destinée au dépôt et à la diffusion de documents scientifiques de niveau recherche, publiés ou non, émanant des établissements d'enseignement et de recherche français ou étrangers, des laboratoires publics ou privés. 


\section{Journal Pre-proof}

A novel oxalate-based three dimensional polymorphs supramolecular compounds: Synthesis, spectroscopic characterization, magnetic and photocatalytic properties

Rihab Dridi, Saoussen Namouchi Cherni, Farid Fettar, Nassira Chniba-Boudjada, Mohamed Faouzi Zid

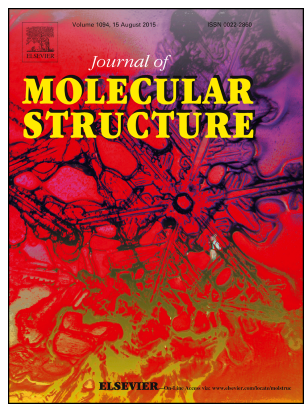

PII: S0022-2860(19)31682-5

DOI: https://doi.org/10.1016/j.molstruc.2019.127573

Reference: MOLSTR 127573

To appear in: Journal of Molecular Structure

Received Date: 17 September 2019

Revised Date: 1 December 2019

Accepted Date: 10 December 2019

Please cite this article as: R. Dridi, S.N. Cherni, F. Fettar, N. Chniba-Boudjada, M.F. Zid, A novel oxalate-based three dimensional polymorphs supramolecular compounds: Synthesis, spectroscopic characterization, magnetic and photocatalytic properties, Journal of Molecular Structure (2020), doi: https://doi.org/10.1016/j.molstruc.2019.127573.

This is a PDF file of an article that has undergone enhancements after acceptance, such as the addition of a cover page and metadata, and formatting for readability, but it is not yet the definitive version of record. This version will undergo additional copyediting, typesetting and review before it is published in its final form, but we are providing this version to give early visibility of the article. Please note that, during the production process, errors may be discovered which could affect the content, and all legal disclaimers that apply to the journal pertain.

(C) 2019 Published by Elsevier B.V. 
A novel oxalate-based three dimensional polymorphs supramolecular compounds: Synthesis, spectroscopic characterization, magnetic and photocatalytic properties

Rihab Dridi, ${ }^{\mathrm{a}^{*}}$ Saoussen Namouchi Cherni, ${ }^{\mathrm{a}}$ Farid Fettar, ${ }^{\mathrm{b}}$ Nassira Chniba-Boudjada, ${ }^{\mathrm{b}}$ Mohamed Faouzi Zid ${ }^{\text {a }}$

${ }^{a}$ Université de Tunis El Manar, Faculté des Sciences de Tunis, Département de Chimie, Laboratoire de Matériaux, Cristallochimie et Thermodynamique Appliquée, 2092 Tunis, Tunisie

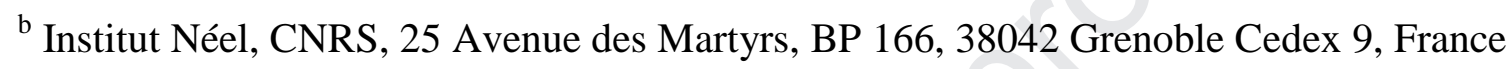

* Corresponding author:

E-mail address : rihab018@live.fr

\section{Graphical abstract}
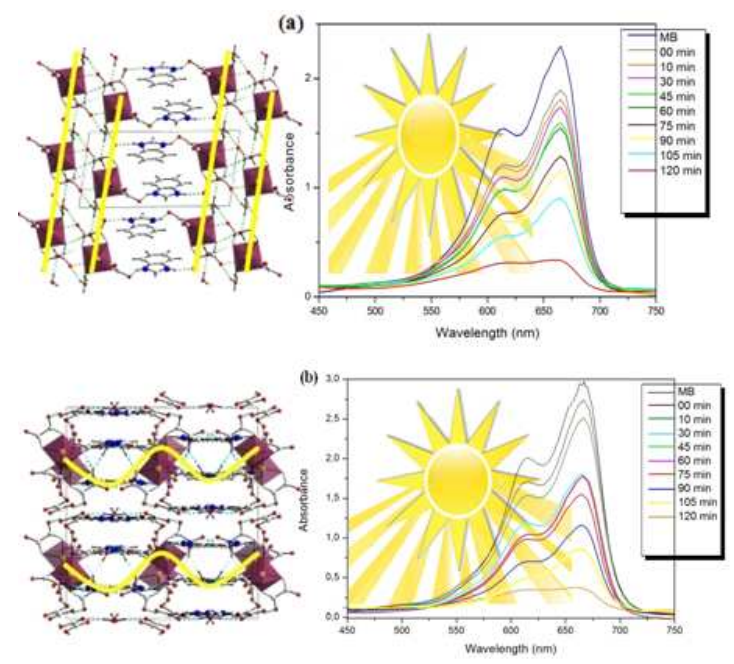
Abstract

Two metal complexes $\left(\mathrm{C}_{7} \mathrm{H}_{7} \mathrm{~N}_{2}\right)\left[\mathrm{Cr}\left(\mathrm{C}_{2} \mathrm{O}_{4}\right)_{2}\left(\mathrm{H}_{2} \mathrm{O}\right)_{2}\right] \cdot 2 \mathrm{H}_{2} \mathrm{O} \quad$ (1) and $\left(\mathrm{C}_{7} \mathrm{H}_{7} \mathrm{~N}_{2}\right)_{3}\left[\mathrm{Cr}\left(\mathrm{C}_{2} \mathrm{O}_{4}\right)_{3}\right]\left(\mathrm{H}_{2} \mathrm{C}_{2} \mathrm{O}_{4}\right) \cdot 3 \mathrm{H}_{2} \mathrm{O}$ (2), have been synthesized by self-assembly of a benzimidazole ligand and oxalic acid anion with chromium(III) as metal. The complexes (1) and (2) were characterized by single crystal X-ray diffraction, TG analysis and spectroscopy techniques. The molecular structure of complexes (1) and (2) appear to be a modular associate consisting of a complex anion containing trivalent $\mathrm{Cr}$ as the central atom, a bridging hydrogen oxalate anion, a monoprotonated benzimidazole acting as the counter-cation and water molecules. The atomic arrangement of complexes (1) and (2) can be described as inorganic layers of anionic chromium complex and water molecules between which organic cations $\left(\mathrm{C}_{7} \mathrm{H}_{7} \mathrm{~N}_{2}\right)^{+}$are located. The crystal packing of complexes (1) and (2) is ensured by extensive $\mathrm{O}-\mathrm{H} . . . \mathrm{O}$ and N-H...O hydrogen bonds. In addition, the magnetic properties of the complex (1) were determined in the range $1.8-300 \mathrm{~K}$ showing a very weak antiferromagnetic interactions between $\mathrm{Cr}$ (III) centers with a little contribution of ZFS effect. Moreover, complexes (1) and (2) exhibit significant degradation of methylene blue (MB) under sunlight irradiation.

Keywords: Structural determination; optical characterization; magnetic properties; photocatalytic application.

\section{Introduction}

The design and construction of new functional inorganic-organic hybrid coordination compounds have been one of the pioneer fields in current crystal engineering due to compositional diversity, structural versatility and potential applications in diverse areas such as catalytic, optical, magnetism, electrochemistry, and medicine [1-3].

One of the most important area of application is certainly the field of photocatalysis. Nowadays, an extensive work has been focused on the photocatalytic degradation of organic dyes using inorganic-organic hybrid complexes due to their non-toxicity, good photocatalytic properties and low production costs [4-6]. It must be pointed out that organic dyes released via wastewaters represent an important source of pollution, leading to eutrophication and perturbation of aquatic life [7]. On the other side, inorganic-organic hybrid complexes being magnetic systems involving $\mathrm{H}$-bonds, have also attracted attention of researchers due to the possibility of controlling the exchange coupling between parts of molecular quantum systems, for example in spin crossover materials [8] or nanomagnets [9]. 
Motivated by the above-mentioned properties, we have decided to design a new multifunctional hybrid organic-inorganic compounds based on supramolecular concepts combining these properties. In fact, the self-assembly of the desired functional compounds depends on many factors, such as the ligand-metal molar ratio, temperature, $\mathrm{pH}$, solvent, the coexisting neutral ligands and the nature of the organic ligands [10-12]. Among them, we judiciously chose the oxalate dianion which belongs to the family of dicarboxylate type ligands, owing the specific disposition of the $\mathrm{O}$ donor atoms, acting as chelate. Thus, in the presence of transition metal ions, it offers a unique mode of coordination based on the formation of five-membered rings. On the other hand, it has been proved that oxalate ligand act as efficient mediators of the magnetic interaction between the paramagnetic transition metal centers offering a great opportunity to develop new magnetic materials and explore magneto-structural correlations [13,14]. Indeed, benzimidazole and its derivates have received extensive attention for their high structural stability and we have used benzimidazole as ligand due to its larger conjugated $\pi$-system, capable of acting as hydrogen bond donors and in $\pi-\pi$ stacking interaction [15]. It is worth noting that properties ofthe orbital magnetic moments of $\mathrm{Cr}$ (III) complexes have attracted many researchers owing the ability of optimizing magnetic coupling and zero-field splitting [16,17]. Moreover, the known oxidative $\left({ }^{2} \mathrm{E}\right)$ excited state of $\mathrm{Cr}(\mathrm{III})$ can be used for water splitting and $\mathrm{O}_{2}$ production [18].

Based on the above considerations and in the hope of obtaining new multifunctional organicinorganic compounds, oxalic acid and benzimidazole ligand assembled with the stable chromium (III) ion, were used to achieve two novel complexes: $\left(\mathrm{C}_{7} \mathrm{H}_{7} \mathrm{~N}_{2}\right)\left[\mathrm{Cr}\left(\mathrm{C}_{2} \mathrm{O}_{4}\right)_{2}\left(\mathrm{H}_{2} \mathrm{O}\right)_{2}\right] \cdot 2 \mathrm{H}_{2} \mathrm{O}$ (1) and $\left(\mathrm{C}_{7} \mathrm{H}_{7} \mathrm{~N}_{2}\right)_{3}\left[\mathrm{Cr}\left(\mathrm{C}_{2} \mathrm{O}_{4}\right)_{3}\right]\left(\mathrm{H}_{2} \mathrm{C}_{2} \mathrm{O}_{4}\right) \cdot 3 \mathrm{H}_{2} \mathrm{O}$ (2). On both compounds, the single crystal X-ray structures were determined; the infrared and UVvisible spectra were acquired and the thermogravimetric analyses were made. Furthermore, magnetic measurements and photocatalytic properties were also explored.

\section{Experimental}

\subsection{Material and methods}

All reagents and solvents for the syntheses were purchased from commercial sources and used as received without further purification. Methylene blue was bought from Merck. Infrared spectrum on $\mathrm{KBr}$ pellets was recorded on a Nicolet 470 FTIR spectrophotometer, in the range $4000-400 \mathrm{~cm}^{-1}$. X-ray powder diffraction measurements were performed on a D8 ADVANCE BRUKER diffractometer using $\mathrm{Cu}-\mathrm{K}_{\alpha}$ radiations and equipped with Lynxeye accelerator. 
Thermogravimetric analysis (TGA) was carried out on a Setaram TAG-24 thermoanalyser instrument, under Ar at a heating rate of $10^{\circ} \mathrm{C}$ per min. The UV-Visible absorption spectra were obtained on a $2802 \mathrm{UV} / \mathrm{Vis}$ spectrophotometer (UNICO) in 250-750 nm region. Magnetic susceptibility measurements under $0.5 \mathrm{~T}$ magnetic field in the range $1.88-300 \mathrm{~K}$ were performed with quantum design (superconducting quantum interference device SQUID) magnetometer. All measurements were performed on polycrystalline samples. Pascal's constants were used to estimate the diamagnetic corrections, which were subtracted from the experimental susceptibilities to give the corrected molar magnetic susceptibilities.

\subsection{Preparations of the complexes}

\subsubsection{Synthesis of $\left(\mathrm{C}_{7} \mathrm{H}_{7} \mathrm{~N}_{2}\right)\left[\mathrm{Cr}\left(\mathrm{C}_{2} \mathrm{O}_{4}\right)_{2}\left(\mathrm{H}_{2} \mathrm{O}\right)_{2}\right] .2 \mathrm{H}_{2} \mathrm{O}$}

To a solution containing oxalic acid dihydrate $(2 \mathrm{mmol}, 252.2 \mathrm{mg})$ and benzimidazole $\left(\mathrm{C}_{7} \mathrm{H}_{6} \mathrm{~N}_{2}\right)$ (1 mmol, $118.14 \mathrm{mg}$ ) dissolved in $10 \mathrm{ml}$ of $\mathrm{H}_{2} \mathrm{O} / \mathrm{ETOH}$ mixture (1:1 by volume), an aqueous solution of the chromium nitrate nonahydrate $(1 \mathrm{mmol}, 400.15 \mathrm{mg}$ dissolved in 10 $\mathrm{mL} \mathrm{H}_{2} \mathrm{O}$ ) was added dropwise. The reaction mixture obtained was heated at $50^{\circ} \mathrm{C}$ for an hour with continuous stirring. The resulting solution was then cooled down to room temperature and kept unperturbed for the slow evaporation of the solvent. Purple single crystals suitable for X-ray diffraction analysis were obtained after one week (scheme 1(a)).

Yield $72 \%$; m.p. $=276^{\circ} \mathrm{C}$. Main IR absorption bands observed for (1) $\left(\mathrm{KBr}\right.$ pellet, $\left.\mathrm{cm}^{-1}\right)$ are : $3120 \mathrm{~m}(v \mathrm{O}-\mathrm{H}), 1671 \mathrm{~s}\left(v_{\text {asy }} \mathrm{C}=\mathrm{O}\right), 1384 \mathrm{~m}\left(v_{\mathrm{sy}} \mathrm{C}=\mathrm{O}\right), 1241 \mathrm{~m}(\mathrm{C}$ aromatic ring $-\mathrm{N}), 817$ $\mathrm{w}(\delta \mathrm{C}=\mathrm{O}), 470 \mathrm{w}(\mathrm{Cr}-\mathrm{O})$.

\subsubsection{Synthesis of $\left(\mathrm{C}_{7} \mathrm{H}_{7} \mathrm{~N}_{2}\right)_{3}\left[\mathrm{Cr}\left(\mathrm{C}_{2} \mathrm{O}_{4}\right)_{3}\right]\left(\mathrm{H}_{2} \mathrm{C}_{2} \mathrm{O}_{4}\right) .3 \mathrm{H}_{2} \mathrm{O}$ (2)}

Chromium(III) nitrate nonahydrate $(400.15 \mathrm{mg}, 1 \mathrm{mmol})$ was dissolved in $10 \mathrm{~mL}$ of water. This solution was allowed to react with oxalic acid dihydrate $(2 \mathrm{mmol}, 252.2 \mathrm{mg}$ ) dissolved in $5 \mathrm{~mL}$ of water. An aqueous solution $(10 \mathrm{~mL})$ of benzimidisazole $(1 \mathrm{mmol}, 118.14 \mathrm{mg})$ was added drop wise to the above purple solution with continuous stirring. The combined solution was stirred and left to evaporate for several hours. The resultant crystals were obtained after 5 days (scheme 1(b)). Yield $83 \%$; m.p. $=283^{\circ} \mathrm{C}$. Main IR absorption bands observed for (2) $\left(\mathrm{KBr}\right.$ pellet, $\left.\mathrm{cm}^{-1}\right)$ are $: 2955 \mathrm{~m}(v \mathrm{O}-\mathrm{H}), 1641 \mathrm{~s}\left(v_{\text {asy }} \mathrm{C}=\mathrm{O}\right), 1368 \mathrm{~m}\left(v_{\mathrm{sy}} \mathrm{C}=\mathrm{O}\right), 1255 \mathrm{~m}(\mathrm{C}$ aromatic ring $-\mathrm{N}), 808 \mathrm{w}(\delta \mathrm{C}=\mathrm{O}), 458 \mathrm{w}(\mathrm{Cr}-\mathrm{O})$.

\subsection{Photocatalytic experiments}


The photocatalytic activities of compound (1) and compound (2) were evaluated for degradation of methylene blue (MB). Experiments were carried out under sunlight irradiation as follows: $20 \mathrm{mg}$ of the solid sample was dispersed into a tube containing $100 \mathrm{~mL}$ of methylene blue solution $(10 \mathrm{mg} / \mathrm{L})$. The reaction was stirred in a dark environment for over $1 \mathrm{~h}$ in order to eliminate adsorption effects between the catalyst and solution. The solution was then exposed to sunlight irradiation. At given intervals, $5 \mathrm{~mL}$ of reaction solution was periodically taken and dispersed powders were removed by centrifugation. The resulting solutions were analyzed with a UV/Vis spectrophotometer. Degradation of the organic dyes under the same conditions, without any complexes was also carried out for comparison.

Considering the initial absorbance values of the dye solution as $\mathrm{A}_{0}$, and the absorbance values at time $t$ as $A_{t}$, the degradation efficiency (D) of the dye is defined as follows:

$\mathrm{D}=\left[\left(\mathrm{A}_{0}-\mathrm{A}_{\mathrm{t}}\right) / \mathrm{A}_{0}\right] \times 100$

\subsection{X-Ray crystallography}

Single crystal X-ray diffraction data for (1) and (2) were collected at $298 \mathrm{~K}$ on Kappa CCD diffractometer by using graphite-monochromated Mo- $\mathrm{K}_{\alpha}(\lambda=0.71073 \AA)$ radiation. The structures were solved by Direct methods using SIR-2014 and refined against $\mathrm{F}^{2}$ on all data by full-matrix least-squares methods using SHELXL-2014/7 [19,20].

Metal atoms in each complex were located from the $E$-maps and non-hydrogen atoms were located in successive difference Fourier syntheses and refined with anisotropic thermal parameters on $\mathrm{F}^{2}$. The hydrogen atoms of the aromatic organic ligands bonded to carbon were inserted at calculated positions with $\mathrm{C}-\mathrm{H}$ distance of $0.93 \AA$. While those attached to nitrogen were placed with $\mathrm{d}(\mathrm{N}-\mathrm{H})=0.86 \AA$. All were included as riding contributions with isotropic displacement parameters 1.2 - 1.5 times those of the attached atoms. The hydrogen atoms of the water molecules were found in a difference Fourier map and refined with restraints: $\mathrm{d}(\mathrm{O}-\mathrm{H})=0.85(1) \AA, \mathrm{d}(\mathrm{H} . . . \mathrm{H})=1.387(2) \AA$ and $U_{\text {iso }}(\mathrm{H})=1.5 U$ eq $(\mathrm{O})$. The molecular plots were drawn with the Diamond 3.0 program [21]. Relevant crystallographic data and data collection parameters are summarized in Table 1. 


\section{Journal Pre-proof}

Table 1. Summary of the crystal data and structure refinement for $\left(\mathrm{C}_{7} \mathrm{H}_{7} \mathrm{~N}_{2}\right)\left[\mathrm{Cr}\left(\mathrm{C}_{2} \mathrm{O}_{4}\right)_{2}\left(\mathrm{H}_{2} \mathrm{O}\right)_{2}\right] \cdot 2 \mathrm{H}_{2} \mathrm{O}(\mathbf{1})$ and $\left(\mathrm{C}_{7} \mathrm{H}_{7} \mathrm{~N}_{2}\right)_{3}\left[\mathrm{Cr}\left(\mathrm{C}_{2} \mathrm{O}_{4}\right)_{3}\right]\left(\mathrm{H}_{2} \mathrm{C}_{2} \mathrm{O}_{4}\right) 3 . \mathrm{H}_{2} \mathrm{O}$ (2)

\begin{tabular}{|c|c|c|}
\hline Formula & $\mathrm{C}_{11} \mathrm{H}_{15} \mathrm{CrN}_{2} \mathrm{O}_{12}$ & $\mathrm{C}_{27} \mathrm{H}_{29} \mathrm{CrN}_{6} \mathrm{O}_{19}$ \\
\hline Formula weight & 419.25 & 817.58 \\
\hline Crystal system & Triclinic & Orthorhombic \\
\hline Space group & P-1 & Pbca \\
\hline Volume $\left(\AA^{3}\right)$ & $826.4(3)$ & $6809(2)$ \\
\hline $\mathrm{Z}$ & 2 & 8 \\
\hline $\mathrm{a}(\AA)$ & $7.245(1)$ & $18.029(4)$ \\
\hline $\mathrm{b}(\AA)$ & $7.725(2)$ & $19.123(4)$ \\
\hline c $(\AA)$ & $15.162(3)$ & $19.479(4)$ \\
\hline$\alpha\left(^{\circ}\right)$ & $97.37(1)$ & 90 \\
\hline$\beta\left(^{\circ}\right)$ & $98.17(2)$ & 90 \\
\hline$\gamma\left({ }^{\circ}\right)$ & $96.04(1)$ & 90 \\
\hline Temperature (K) & 298 & 298 \\
\hline$\rho\left(\mathrm{g} . \mathrm{cm}^{-3}\right)$ & 1.685 & 1.595 \\
\hline$\mu\left(\mathrm{mm}^{-1}\right)$ & 0.76 & 0.43 \\
\hline$\theta$ range $\left(^{\circ}\right)$ & $2.7-27$ & $1.90-30.00$ \\
\hline Crystal size $\left(\mathrm{mm}^{3}\right)$ & $0.38 \times 0.26 \times 0.16$ & $0.40 \times 0.32 \times 0.21$ \\
\hline $\mathrm{F}(000)$ & 430 & 3368 \\
\hline Index ranges & $-9 \leq \mathrm{h} \leq 8,-9 \leq \mathrm{k} \leq 9,-19 \leq 1 \leq 19$ & $-25 \leq \mathrm{h} \leq 24,-26 \leq \mathrm{k} \leq 26,-27 \leq 1 \leq 27$ \\
\hline Total data collected & 7051 & 117016 \\
\hline Independent reflections & 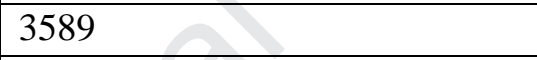 & 9913 \\
\hline $\begin{array}{l}\text { Reflections with } \\
\mathrm{I}>2 \sigma(\mathrm{I})\end{array}$ & 3330 & 7966 \\
\hline Rint & 0.017 & 0.057 \\
\hline Goodness-of-fit on $\mathrm{F}^{2}$ & 1.11 & 1.17 \\
\hline $\mathrm{R}(\mathrm{F})[\mathrm{I}>2 \sigma(\mathrm{I})]^{\mathrm{a} /}$ all data & $0.029 / 0.032$ & $0.036 / 0.053$ \\
\hline $\begin{array}{l}\mathrm{WR}\left(\mathrm{F}^{2}\right)[\mathrm{I}>2 \sigma(\mathrm{I})]^{\mathrm{b}} / \text { all } \\
\text { data }\end{array}$ & $0.082 / 0.084$ & $0.088 / 0.105$ \\
\hline Residuals $\left(\mathrm{e} . \AA^{-3}\right)$ & 0.32 and -0.36 & 0.37 and -0.60 \\
\hline
\end{tabular}

\section{Results and discussion}

\subsection{Crystal structures}

The crystal analysis reveals that complex (1) is formed by one $\left[\mathrm{Cr}(\mathrm{ox})_{2}\left(\mathrm{H}_{2} \mathrm{O}\right)_{2}\right]^{-}$anion, $\left(\mathrm{C}_{7} \mathrm{H}_{7} \mathrm{~N}_{2}\right)^{+}$cation, and two water molecules of crystallization (Figure 1). The central $\mathrm{Cr}^{\mathrm{III}}$ ion of the complex anion is hexacoordinated by two oxygen atoms from water molecules in cis position and four carboxylate oxygen atoms. 

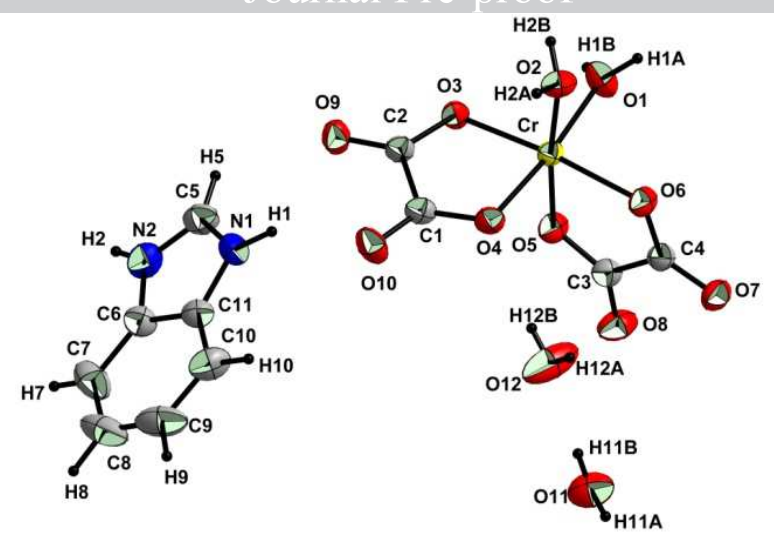

Figure 1. A view of the asymmetric unit of (1) with the atom numbering scheme.

Displacement ellipsoids are drawn at the $50 \%$ probability level and $\mathrm{H}$ atoms are represented as spheres of arbitrary radius

The three diagonal angles of metal polyhedron $\left[172.92(5)^{\circ}\right.$ to $\left.174.35(5)^{\circ}\right]$ deviate from linearity, therefore the coordination geometry around $\mathrm{Cr}(\mathrm{III})$ atoms is a distorted octahedron built up by two $\mathrm{O}$ atoms $(\mathrm{O} 1, \mathrm{O} 2)$ from two cis water molecules and four $\mathrm{O}$ atoms $(\mathrm{O} 3, \mathrm{O} 4$, O5, O6) from two chelating oxalate dianions.

In order to calculate the octahedron deviation it is appropriate to use $\Sigma$ parameter, which is the sum of the deviation away from $90^{\circ}$ of the twelve possible $\mathrm{O}-\mathrm{Cr}-\mathrm{O}$ bite angles. As such, the value for an ideal octahedron is $\Sigma=0$, so that higher the value, the greater is the distortion. The formula used for the calculation is the following [22]:

$$
\Sigma=\sum_{i=1}^{12}\left|90-\alpha_{i}\right|
$$

In the case of complex (1), $\Sigma=32.52$ indicating a distorted octahedral geometry for the metal coordination sphere. The $\mathrm{O}-\mathrm{Cr}-\mathrm{O}$ bite angles $\left(82.17(5)^{\circ}\right.$ to $\left.93.72(6)^{\circ}\right)$ are far from the ideal one range from of $90^{\circ}$ because of the usual small bite size of five-membered planar chelate rings formed by the bidentate oxalate ligand. Selected bond lengths and angles are gathered in Table S 1. The Cr-O(ox) bond lengths of $1.963(2)^{\circ}$ and those of $\mathrm{Cr}-\mathrm{O}$ (water) of $1.978(2)^{\circ}$ are comparable with the values reported for similar compounds containing the $\left[\mathrm{Cr}\left(\mathrm{C}_{2} \mathrm{O}_{4}\right)_{2}\left(\mathrm{H}_{2} \mathrm{O}\right)_{2}\right]^{-}$motif, completed with various uncoordinated cations [23,24].

The anionic units are interlined with each other by means of O-H...O hydrogen bonds, through coordinated water molecules (O1 and $\mathrm{O} 2)$ and outer oxygen atoms from oxalate ligand (O7 and $\mathrm{O} 8)$ giving rise to a cyclic motif $\mathrm{R}_{2}^{2}(12)$, and through uncoordinated water 
molecules (O11 and $\mathrm{O} 12)$ and inner oxalate $\mathrm{O}$ atoms (O4 and $\mathrm{O} 6)$ giving rise to different types of rings $\mathrm{R}_{4}^{4}(12), \mathrm{R}_{4}^{3}(12), \mathrm{R}_{4}^{4}(16)$ and $\mathrm{R}_{4}^{4}(20)$ [25]. This assembly generates an infinite two dimensional (2-D) layers parallel to (001) plane (Figure 2). Details of all hydrogen bond interactions are given in Table 2.
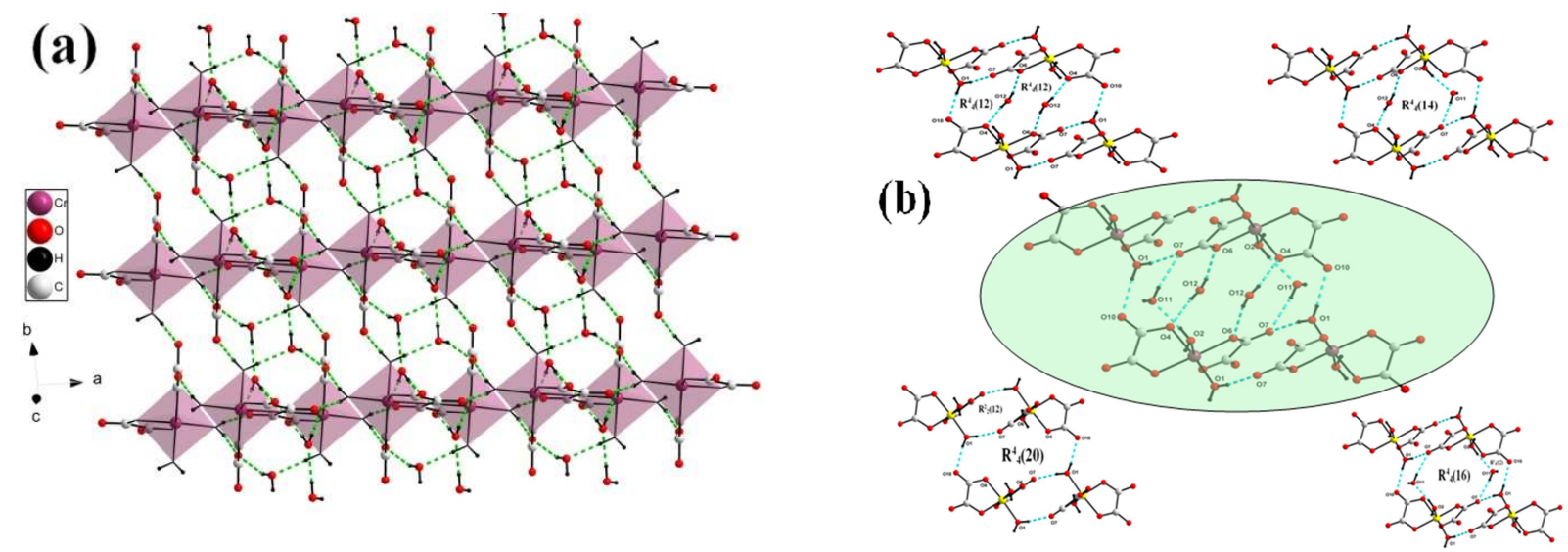

Figure 2. (a) View of a 2-D network of (1) through adjacent chains which are formed by intermolecular hydrogen bonding interactions; (b) View of 5 identifying the graph set motifs within the hydrogen bonded sheets

Table 2. Hydrogen bonds of complex (1)

\begin{tabular}{|c|c|c|c|c|}
\hline $\mathrm{D}-\mathrm{H} \cdots \mathrm{A}$ & D-H & $\mathrm{H} \cdots \mathrm{A}$ & $\mathrm{D} \cdots \mathrm{A}$ & $\mathrm{D}-\mathrm{H} \cdots \mathrm{A}$ \\
\hline O1-H1A $\cdots$ O7i & $0.80(2)$ & $1.88(2)$ & $2.675(2)$ & $172(2)$ \\
\hline O1-H1B $\cdots$ O10ii & $0.72(3)$ & $1.99(3)$ & $2.697(2)$ & 169.42 \\
\hline $\mathrm{O} 2-\mathrm{H} 2 \mathrm{~A} \cdots \mathrm{O} 11$ & $0.77(3)$ & $1.84(3)$ & $2.601(3)$ & $173(3)$ \\
\hline O2-H2B $\cdots$ O8iii & $0.79(3)$ & $1.97(3)$ & $2.741(2)$ & 162.84 \\
\hline O11-H11A..O7iv & $0.74(4)$ & $2.23(4)$ & $2.935(3)$ & $162(4)$ \\
\hline O11-H11B $\cdots$ O12iii & $0.78(4)$ & $1.93(4)$ & $2.702(3)$ & 178.06 \\
\hline O12-H12A $\cdots$ O6i & $0.75(4)$ & $2.11(4)$ & $2.847(4)$ & 170.29 \\
\hline $\mathrm{O} 12-\mathrm{H} 12 \mathrm{~B} \cdots \mathrm{O} 4$ & $0.75(4)$ & $2.15(4)$ & $2.892(3)$ & $173(3)$ \\
\hline N1-H1 $\cdots$ O10v & 0.86 & 2.27 & $3.043(3)$ & 151 \\
\hline $\mathrm{N} 2-\mathrm{H} 2 \cdots \mathrm{O} 8$ & 0.86 & 1.95 & $2.791(3)$ & 168 \\
\hline
\end{tabular}

Symmetry code : (i) $-x+2 .-y+1 .-z+2$; (ii) $x+1 . y \cdot z$; (iii) $x . y-1 . z$; (iv) $-x+1 .-y+1 .-z+2$; (v) $-x+1 .-y+1 .-z+1$.

As shown in Figure 3, the neutralization of the negative charge of the anionic part is assured by independent benzimidazole cations localized in the interlayer spacing . 


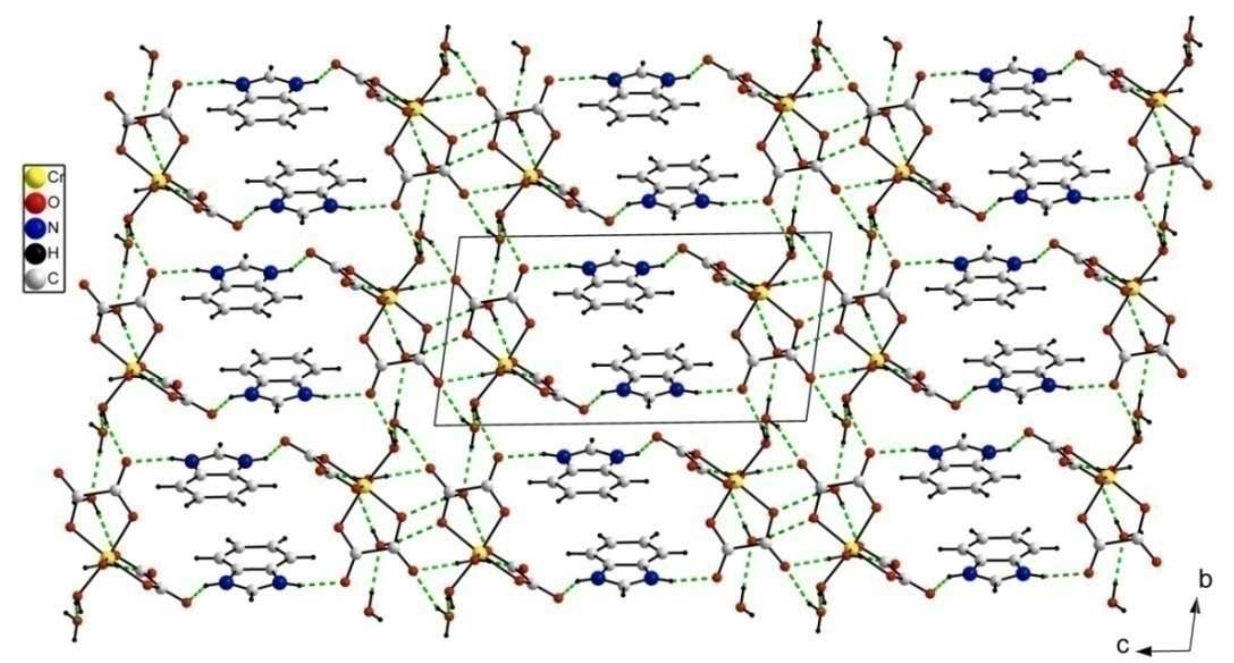

Figure 3. Projection of the $\left(\mathrm{C}_{7} \mathrm{H}_{7} \mathrm{~N}_{2}\right)\left[\mathrm{Cr}\left(\mathrm{C}_{2} \mathrm{O}_{4}\right)_{2}\left(\mathrm{H}_{2} \mathrm{O}\right)_{2}\right] .2 \mathrm{H}_{2} \mathrm{O}$ structure along the $a$ axis showing the hydrogen-bonded network

The geometric features of the organic cations show that the benzimidazole ligand is planar and the average $\mathrm{C}-\mathrm{C}(1.380(3) \AA)$ and $\mathrm{C}-\mathrm{N}(1.348(3) \AA$ ) bond lengths, and the average angles $\left(108^{\circ}\right)$ within the rings are in a good agreement with those reported in the literature [26,27]. It is worth noting that benzimidazole cations have two $\mathrm{H}$-bond sites well positioned to interact with the two outer $\mathrm{O}$ of an oxalate. Figure 4 shows well that the interconnection between the inorganic layers and the benzimidazole units is achieved by hydrogen-bonding that link the first amino N1-H1 group to the free $\mathrm{O} 9$ oxalate $\mathrm{O}$ atoms and the second amino N2-H2 group to the outer $\mathrm{O} 8$ oxalate $\mathrm{O}$ atoms, forming a cations-anions interaction type by connecting the positive and the negative layers. As a consequence, no $\pi-\pi$ interaction is present between the benzimidazole molecules in complex (1).

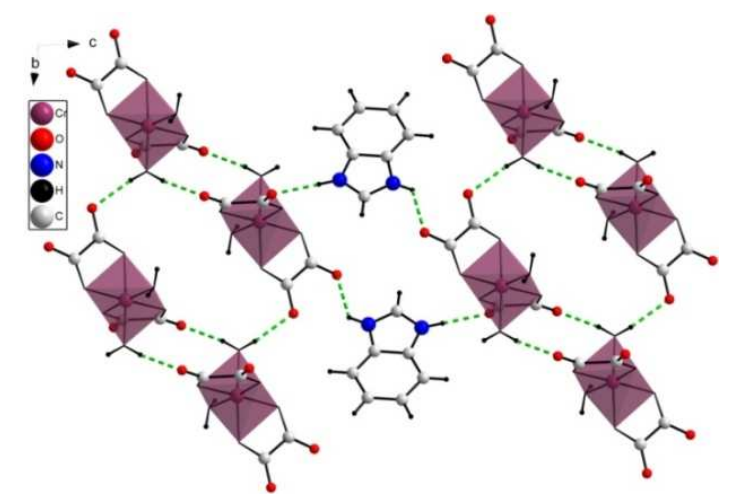

Figure 4. Intermolecular O-H...O and N-H...O hydrogen bonds present in complex (1)

Complex (1) represents a case of such a combination of different hydrogen bonding that contributes to the self assembly process and leads to 3-D packing . 
Complex (2) is made up of one $\left[\mathrm{Cr}\left(\mathrm{C}_{2} \mathrm{O}_{4}\right)_{3}\right]^{3-}$ anion, three $\left(\mathrm{C}_{7} \mathrm{H}_{7} \mathrm{~N}_{2}\right)^{+}$organic cations, one neutral oxalic acid molecule $\left(\mathrm{C}_{2} \mathrm{H}_{2} \mathrm{O}_{4}\right)$ and three $\mathrm{H}_{2} \mathrm{O}$ molecules (Figure 5).
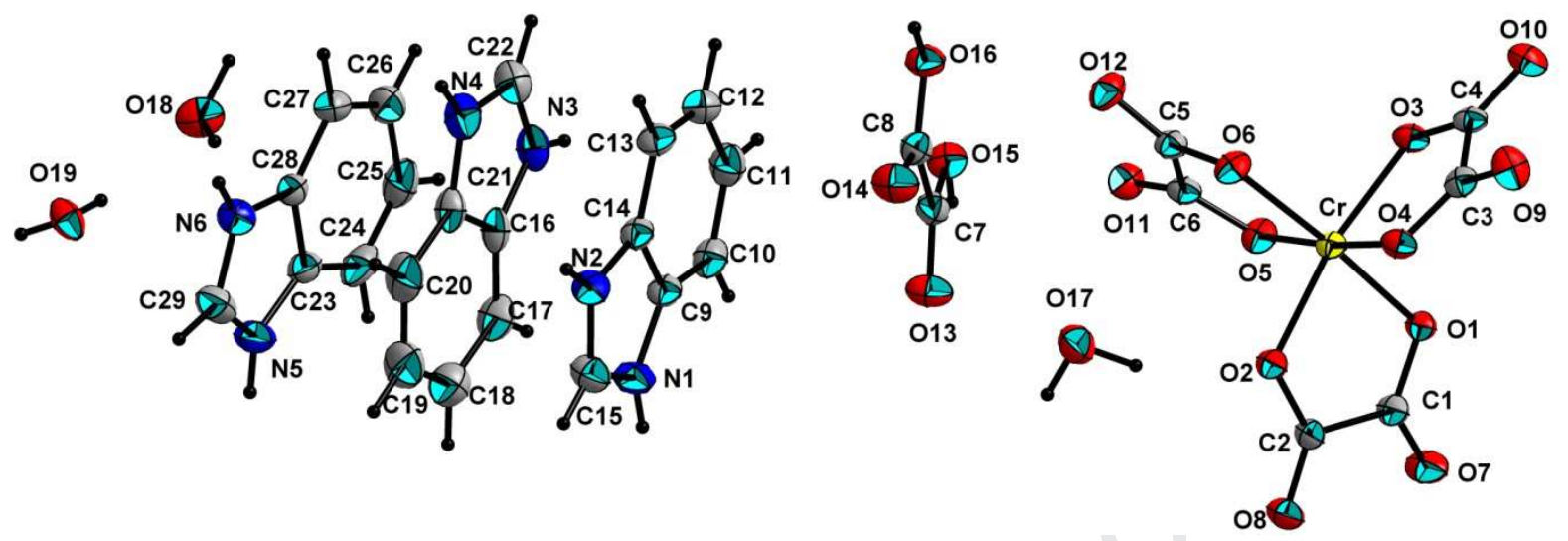

Figure 5. A view of the asymmetric unit of (2) with the atom numbering scheme.

Displacement ellipsoids are drawn at the $50 \%$ probability level and $\mathrm{H}$ atoms are represented as spheres of arbitrary radius

In (2), the $\mathrm{Cr}^{\mathrm{III}}$ cation shows a slightly distorted octahedral environment which is formed by six oxygen atoms from three chelating oxalate groups. The values of the chelate angles $\alpha$ $\left(82.24(4)^{\circ}, 82.27(4)^{\circ}\right.$ and $\left.82.48(5)^{\circ}\right)$ are significantly smaller than those of an ideal octahedron $\left(\alpha=90^{\circ}\right)$. As calculated for complex (1), the value of $\Sigma$ parameter of 32.02 shows well the distortion of the octahedron.

The Cr-O distances are in the range of 1.957(1) to 1.983(1) $\AA$ and the $\mathrm{O}-\mathrm{Cr}-\mathrm{O}$ angles are in the range of 82.24(4) - 174.77(5). These values are as expected for this type of bonding and similar bond distances and angles have been observed earlier in similar compounds [28,29]. The detailed bond distances and bond angles are shown in Table 2.

In fact, structure (2) is characterized by the presence of free oxalic acid unit, in which two sets of carbon-oxygen oxalate bond distances are observed. The shortest values of 1.209(2) $\AA$ and 1.201(2) $\AA$, belonging to C7-O13 and C8-O14, respectively, are characterized by their greater double bond character. However bond distances of C7-O15 and C8-O16 are somewhat longer. The ranges values of these bonds are 1.306(2) $\AA$ and 1.305(2) $\AA$. The differences in the C-O bond lengths are due to the localization of the double vs single bond: one set is $\mathrm{C}=\mathrm{O}$, while the other is $\mathrm{C}-\mathrm{O}-\mathrm{H}$. The oxalate $\mathrm{C}-\mathrm{C}$ bond distances are in the range of 1.543(3) $\AA$ reflecting carbon-carbon single bond character. 
The structure (2) can be described as inorganic layers formed by $\left[\mathrm{Cr}\left(\mathrm{C}_{2} \mathrm{O}_{4}\right)_{3}\right]^{3-}$ units and free oxalic acid molecules parallel to (100) plane intercalated by sheet of organic cations $\left(\mathrm{C}_{7} \mathrm{H}_{7} \mathrm{~N}_{2}\right)^{+}$and free water molecules (Figure 6).

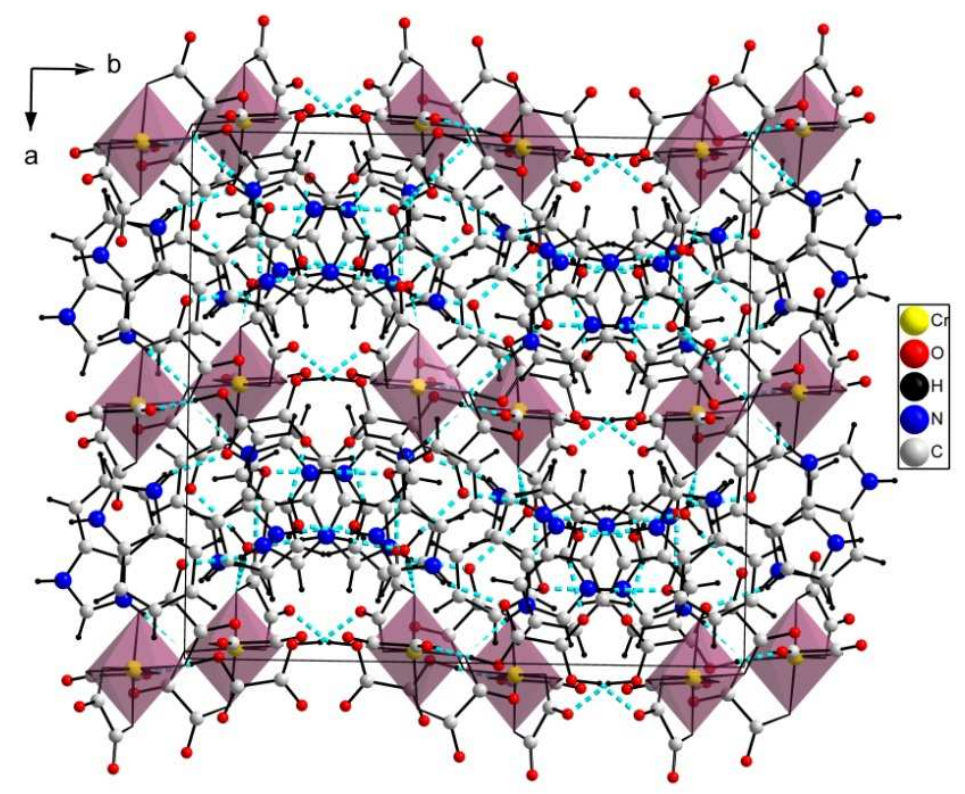

Figure 6. Projection of along the c axis showing the hydrogen-bonded network

In the inorganic layers the cohesion between the mononuclear $\left[\mathrm{Cr}\left(\mathrm{C}_{2} \mathrm{O}_{4}\right)_{3}\right]^{3-}$ dimers, is assured through the free oxalic acid molecules via O-H...O hydrogen bonds (O15-HO1 ‥O11 and

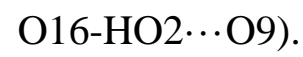

The most fascinating feature of the structure (2) is that the lattice water molecules (O17 and O19) occupy the cavity inside the networks and adopt an interesting orientation so that four $\mathrm{O}-\mathrm{H} \cdots \mathrm{O}$ hydrogen bonds are generated between $(\mathrm{O} 17, \mathrm{O} 19)$ and four oxygen atoms $(\mathrm{O} 2, \mathrm{O} 3$, O8, O10 ) (Figure 7).

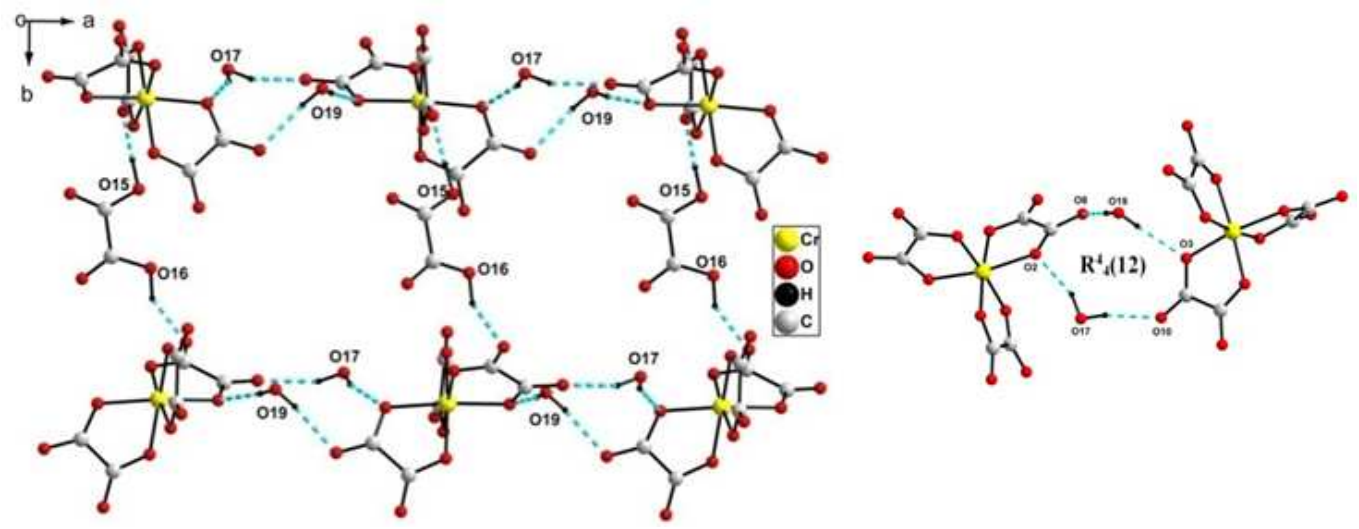

Figure 7. View of a fragments of the molecular structure of $\left(\mathrm{C}_{7} \mathrm{H}_{7} \mathrm{~N}_{2}\right)_{3}\left[\mathrm{Cr}\left(\mathrm{C}_{2} \mathrm{O}_{4}\right)_{3}\right]\left(\mathrm{H}_{2} \mathrm{C}_{2} \mathrm{O}_{4}\right) 3 . \mathrm{H}_{2} \mathrm{O}$ showing well-directional hydrogen bonding interactions 
These linkage connect adjacent anionic moieties and give rise to $\mathrm{R}_{4}^{4}(12)$ rings. The detailed hydrogen bond distances and bond angles are shown in Table 3.

Table 3. Hydrogen bonds of complex (2)

\begin{tabular}{|c|c|c|c|c|}
\hline$D-H \cdots A$ & $\overline{D-H}$ & $\mathrm{H} \cdots A$ & $D \cdots A$ & $D-H \cdots A$ \\
\hline O17-HW6…O2 & $0.92(3)$ & $1.99(3)$ & $2.862(2)$ & $159(3)$ \\
\hline O17-HW3...O10i & $0.85(3)$ & $2.00(3)$ & $2.806(2)$ & $159(3)$ \\
\hline O18-HW4...O10ii & $0.80(3)$ & $2.20(3)$ & $2.958(2)$ & $160(3)$ \\
\hline O18-HW5 $\cdots$ O14iii & $0.93(3)$ & $2.04(4)$ & $2.869(2)$ & $147(3)$ \\
\hline O19-HW1…O8iv & $0.83(3)$ & $1.98(3)$ & $2.804(2)$ & $172(3)$ \\
\hline O19-HW2 $\cdots \mathrm{O} 3 \mathrm{v}$ & $0.79(3)$ & $2.03(3)$ & $2.815(2)$ & $175(3)$ \\
\hline O15-HO1…011vi & $0.99(3)$ & $1.62(3)$ & $2.608(2)$ & $177(3)$ \\
\hline 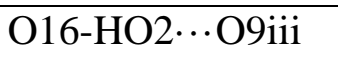 & $0.98(4)$ & $1.76(3)$ & $2.606(2)$ & $142(3)$ \\
\hline N1-H1‥O8vii & 0.86 & $2.07(3)$ & $2.865(2)$ & $154(3)$ \\
\hline N2-H2 $\cdots$ O19viii & 0.86 & $1.90(3)$ & $2.745(2)$ & $167(3)$ \\
\hline 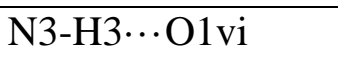 & 0.86 & $1.93(3)$ & $2.770(2)$ & $164(3)$ \\
\hline N4-H4…O17iii & 0.86 & $1.90(3)$ & $2.739(2)$ & $166(3)$ \\
\hline N5-H5 $\cdots$ O13vii & 0.86 & $2.01(3)$ & $2.802(2)$ & $152(3)$ \\
\hline N6-H6 $\cdots \mathrm{O} 18$ & 0.86 & $1.87(3)$ & $2.715(2)$ & $168(3)$ \\
\hline
\end{tabular}

Symmetry code: (i) $\mathrm{x}+1 / 2, \mathrm{y},-\mathrm{z}+1 / 2$; (ii) $\mathrm{x}+1 / 2,-\mathrm{y}+1 / 2,-\mathrm{z}+1$; (iii) $\mathrm{x},-\mathrm{y}+1 / 2, \mathrm{z}+1 / 2$; (iv) $\mathrm{x}$, $\mathrm{y}, \mathrm{z}+1$; (v) $\mathrm{x}+1 / 2, \mathrm{y},-\mathrm{z}+3 / 2$; (vi) $-\mathrm{x}+2,-\mathrm{y},-\mathrm{z}+1$; (vii) $-\mathrm{x}+5 / 2,-\mathrm{y}, \mathrm{z}+1 / 2$; (viii) $\mathrm{x},-\mathrm{y}+1 / 2$, $\mathrm{z}-1 / 2$.

The benzimidazole cations characteristics are similar of structure (1). However, an additional stability of the crystal (2) is afforded by $\pi-\pi$ interactions between the aromatic rings of the cations $\left(\mathrm{C}_{7} \mathrm{H}_{7} \mathrm{~N}_{2}\right)^{+}$. The centroid-centroid distance between two organic rings of benzimidazole is equal to $3.614 \AA$.
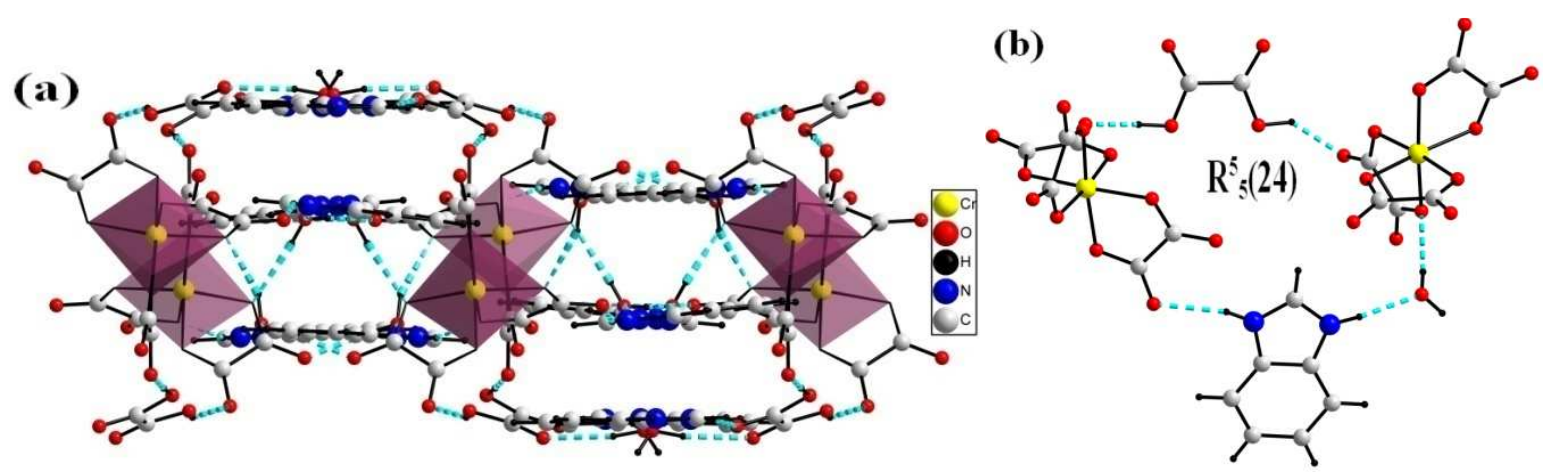

Figure 8. (a) View of the 3-D network of compound (2); (b) A view of the hydrogen bonding in (2), showing the ring motif 
As shown in Figure 8a, the space between the anionic units is occupied by benzimidazole organic cations that cross-link the nearest-neighbor layers by means of $\mathrm{N}-\mathrm{H}$...O (N1-H1...O8, N2-H2...O19, N3-H3...O1, N4-H4...O17， N5-H5...O13, N6-H6...O18) connecting the protonated benzimidazole cations to peripheral $\mathrm{O}$ atoms of oxalate and free water molecule to afford supramolecular inorganic-organic hybrid 3-D architecture (Figure 8b).

\subsection{Powder X-ray diffraction and thermogravimetric studies}

In order to check the purity of complexes (1) and (2), powder X-ray diffraction of the synthesized samples were measured at room temperature. The diffraction pattern was obtained on a D8 ADVANCE Bruker diffractometer using $\left(\mathrm{Cu} \mathrm{K} \mathrm{K}_{\alpha}\right.$ radiation $\left.\lambda=1.54056 \AA\right)$. The measurements were performed with a step size of $0.02^{\circ}$ in the $5-60^{\circ}$ range. The peak positions of experimental patterns show a satisfactory matching with the simulated ones, which clearly indicates good purity of the complexes (1) and (2). The powder diffraction of complexes (1) and (2) are shown in Figure S1 and Figure S2, respectively.

Thermal decomposition patterns of both complexes (1) and (2) were studied by thermogravimetric analysis under Argon atmosphere, with a heating rate of $10^{\circ} \mathrm{C}$ per min between $25^{\circ} \mathrm{C}$ and $600^{\circ} \mathrm{C}$ and showed in Figure 9.

(a)

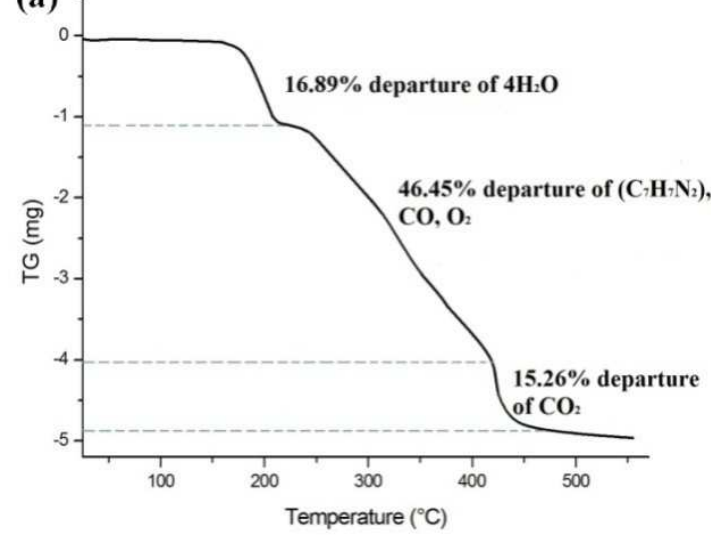

(b)

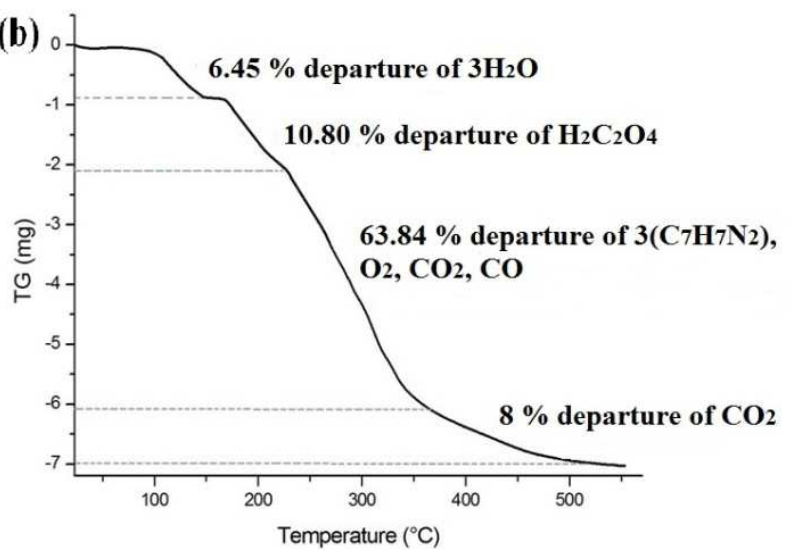

Figure 9. TGA curves of $\left(\mathrm{C}_{7} \mathrm{H}_{7} \mathrm{~N}_{2}\right)\left[\mathrm{Cr}\left(\mathrm{C}_{2} \mathrm{O}_{4}\right)_{2}\left(\mathrm{H}_{2} \mathrm{O}\right)_{2}\right] \cdot 2 \mathrm{H}_{2} \mathrm{O}$ (1) (a) and

$$
\left(\mathrm{C}_{7} \mathrm{H}_{7} \mathrm{~N}_{2}\right)_{3}\left[\mathrm{Cr}\left(\mathrm{C}_{2} \mathrm{O}_{4}\right)_{3}\right]\left(\mathrm{H}_{2} \mathrm{C}_{2} \mathrm{O}_{4}\right) \cdot 3 \mathrm{H}_{2} \mathrm{O} \text { (2) (b) }
$$


The thermal gravimetric analysis curves show that the complexes first lose water molecules, then the ligand split and finally being the residue $\mathrm{Cr}_{2} \mathrm{O}_{3}$.

Thermal gravimetric curve for complex (1) shows that it loses four water molecules (observed $16.89 \%$, calculated $17.17 \%$ ) in the $200^{\circ} \mathrm{C}$ to $220^{\circ} \mathrm{C}$ range. The mass loss of $46.45 \%$ (Calcd. $46.98 \%$ ) was observed in second stage corresponding to the loss of $\left(\mathrm{C}_{7} \mathrm{H}_{7} \mathrm{~N}_{2}\right), \mathrm{CO}$ and $\mathrm{O}_{2}$ in the temperature range $253-422^{\circ} \mathrm{C}$ and probably the formation of $\mathrm{Cr}_{2}\left(\mathrm{CO}_{3}\right)_{3}$ intermediate.

In the final step, the $\mathrm{Cr}_{2}\left(\mathrm{CO}_{3}\right)_{3}$ intermediate degraded into $\mathrm{Cr}_{2} \mathrm{O}_{3}$ in the range $422^{\circ} \mathrm{C}-465^{\circ} \mathrm{C}$ with an approximate weight loss of $15.26 \%$ corresponding to the departure of $\mathrm{CO}_{2}$ which is found to be in good agreement with the calculated weight $15.74 \%$.

Thermal gravimetric curve for complex (2) shows that it degraded in four steps. First stage involved a weight loss mass of $6.45 \%$ (Calculated 6.60\%) corresponding to the elimination of three lattice water molecules in the temperature range $110^{\circ} \mathrm{C}-152^{\circ} \mathrm{C}$. The second stage represented weight loss of $11 \%$ (calculated $10.8 \%$ ) which leads to the removal of free oxalic acid molecule $\left(\mathrm{C}_{2} \mathrm{H}_{2} \mathrm{O}_{4}\right)$ from the temperature range $175^{\circ} \mathrm{C}$ and $237^{\circ} \mathrm{C}$. The third step of the decomposition from $240^{\circ} \mathrm{C}$ to $365^{\circ} \mathrm{C}$, with a mass loss of $63.84 \%$ (calculated $64.94 \%$ ) corresponds to the decomposition of organic part and coordinated oxalate ligand. Fourth stage resulted in mass loss of $8.1 \%$ (Calcd. 8.07\%) due to departure of $\mathrm{CO}_{2}$ and the formation of $\mathrm{Cr}_{2} \mathrm{O}_{3}$ chromium oxide from the decomposition of chromium carbonate.

\subsection{Optical absorption study}

The electronic absorptive spectra of $\left(\mathrm{C}_{7} \mathrm{H}_{7} \mathrm{~N}_{2}\right)\left[\mathrm{Cr}\left(\mathrm{C}_{2} \mathrm{O}_{4}\right)_{2}\left(\mathrm{H}_{2} \mathrm{O}\right)_{2}\right] \cdot 2 \mathrm{H}_{2} \mathrm{O}$ (1) and $\left(\mathrm{C}_{7} \mathrm{H}_{7} \mathrm{~N}_{2}\right)_{3}\left[\mathrm{Cr}\left(\mathrm{C}_{2} \mathrm{O}_{4}\right)_{3}\right]\left(\mathrm{H}_{2} \mathrm{C}_{2} \mathrm{O}_{4}\right) \cdot 3 \mathrm{H}_{2} \mathrm{O}$ (2) were measured in aqueous solution at room temperature. The spectra of complex (1) and (2), show in the visible area two bands at 560 $\mathrm{nm}, 416 \mathrm{~nm}$ for (1) and at $572 \mathrm{~nm}, 424 \mathrm{~nm}$ for (2) corresponding to ${ }^{4} \mathrm{~A}_{2 \mathrm{~g}} \rightarrow{ }^{4} \mathrm{~T}_{2 \mathrm{~g}}\left(v_{1}\right)$ and ${ }^{4} \mathrm{~A}_{2 \mathrm{~g}}$ $\rightarrow{ }^{4} \mathrm{~T}_{1 \mathrm{~g}}(\mathrm{~F})\left(\mathrm{v}_{2}\right)$ transitions, respectively, and one intense band corresponding to charge transfer transition in the ultraviolet region for both compounds (Figure 10) [30].

The value of the crystal field parameter $D_{q}$, Racah parameter $B$ and the unobserved third transition ${ }^{4} \mathrm{~A}_{2 \mathrm{~g}} \rightarrow{ }^{4} \mathrm{~T}_{1 \mathrm{~g}}(\mathrm{P})\left(\mathrm{v}_{3}\right)$ are evaluated from the observed energy bands. Based on Tanabe-Sugano diagram the values of these parameters are found as $1785.7 \mathrm{~cm}^{-1}, 607 \mathrm{~cm}^{-1}$ and $38342 \mathrm{~cm}^{-1}$ for compound (1) and $1751.3 \mathrm{~cm}^{-1}, 591 \mathrm{~cm}^{-1}$ and $37820 \mathrm{~cm}^{-1}$ for compound (2). It is worth noting to mention that the value of $\mathrm{Dq} / \mathrm{B}$ is equal to 2.94 for (1) and 2.96 for (2) which shows that $\mathrm{Cr}^{3+}$ ions for both complexes situated in a strong crystal field sites. 

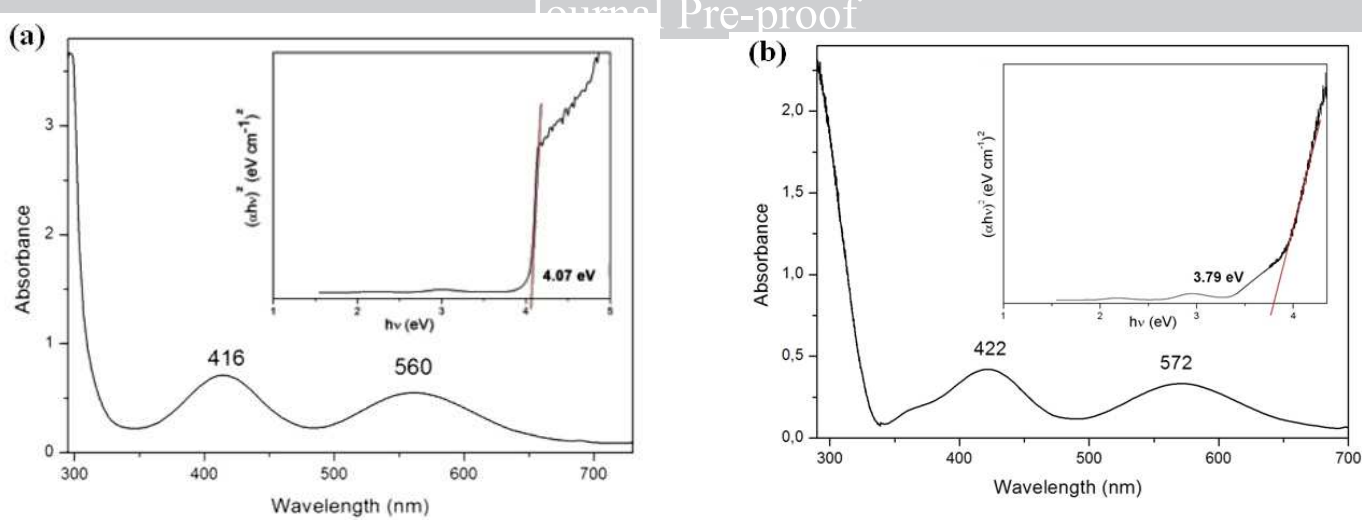

Figure 10. UV-Visible of $\left(\mathrm{C}_{7} \mathrm{H}_{7} \mathrm{~N}_{2}\right)\left[\mathrm{Cr}\left(\mathrm{C}_{2} \mathrm{O}_{4}\right)_{2}\left(\mathrm{H}_{2} \mathrm{O}\right)_{2}\right] .2 \mathrm{H}_{2} \mathrm{O}$ (1) (a) and $\left(\mathrm{C}_{7} \mathrm{H}_{7} \mathrm{~N}_{2}\right)_{3}\left[\mathrm{Cr}\left(\mathrm{C}_{2} \mathrm{O}_{4}\right)_{3}\right]\left(\mathrm{H}_{2} \mathrm{C}_{2} \mathrm{O}_{4}\right) \cdot 3 \mathrm{H}_{2} \mathrm{O}$ (2) (b) with a concentration of 4.7.10 $0^{-3} \mathrm{M}$ and 3.9.10-3, respectively, and a path length $\mathrm{d}$ of $1.0 \mathrm{~cm}$

The values of B for both compounds (1) and (2) are evaluated as $607 \mathrm{~cm}^{-1}$ and $591 \mathrm{~cm}^{-1}$, respectively, which are significantly smaller than the free ion value of $\mathrm{Cr}^{3+}, \mathrm{B}$ free $=918 \mathrm{~cm}^{-1}$. This decrease in B from B free is caused by the effect of bond covalence [31]. The electronic absorptive spectra were also used to determine the experimental band gap by considering the Tauc formula [32]:

$\alpha h v=B\left(h v-E_{g}\right)^{1 / 2}$

where $\alpha$ is the absorption coefficient, $\mathrm{h}$ is Planck's constant, $\mathrm{h} v$ is the photon energy of the incident photon, Eg is the direct band gap energy, and B is a constant.

Using Beer-Lambert's relation, the absorption coefficient $(\alpha)$ can be determined through the relation $\alpha=2.303 \mathrm{~A} / \mathrm{d}$, where A represents the absorbance determined from the UV-Visible spectrum and $d$ is the path length of the quartz cuvette. The optical direct band gap is determined from the intercepts of the extrapolated linear part plots of $(\alpha h v)^{1 / 2}$ versus photon energy (hv) as shown in Figure 10. The obtained value of optical band gap is about $4.07 \mathrm{eV}$ for (1) and $3.79 \mathrm{eV}$ for (2). These values suggested that compound (1) and (2) may respond to UV light and have the potential capacity for catalyzing photodegradation reactions.

\subsection{Photocatalytic reaction}

Recently, much effort has been devoted to studying inorganic-organic hybrid compound as photocatalysts and applying them for degradation of organic dyes. Here, we selected 
methylene blue as the model pollutant of dye contaminants in water to evaluate the photocatalytic effectiveness of complexes (1) and (2). The methylene blue is usually employed as a representative of organic dye which is difficult to decompose in wastes. All photocatalytic reactions were performed under sunlight irradiation in a quartz beaker. For comparison, the photocatalytic process of methylene blue solution without any photocatalysts was also investigated under the same condition.

A sample was taken every $15 \mathrm{~min}$ and analyzed on a UV-Vis spectrophotometer (Figure 11). The photocatalytic degradation of methylene blue solution with the two synthesized compounds was determined by efficiency of degradation $(\%)$ parameter where the efficiency of degradation $(\%)$ is equal to $\mathrm{A}-\mathrm{A}_{0} / \mathrm{A}_{0} . \mathrm{A}_{0}$ is the dye solution absorbance in absence of catalyst, A the absorbance in presence of catalyst after time $t$, this photocatalytic degradation of MB solution with the synthesized two compounds was $79 \%$ for (1) and $83 \%$ for (2) (Figure 12). The results indicate that complexes 1 and 2 possess better degradation ability than previously reported complexes [33-35] and can serve as an excellent candidate for decomposing MB under sunlight irradiation.
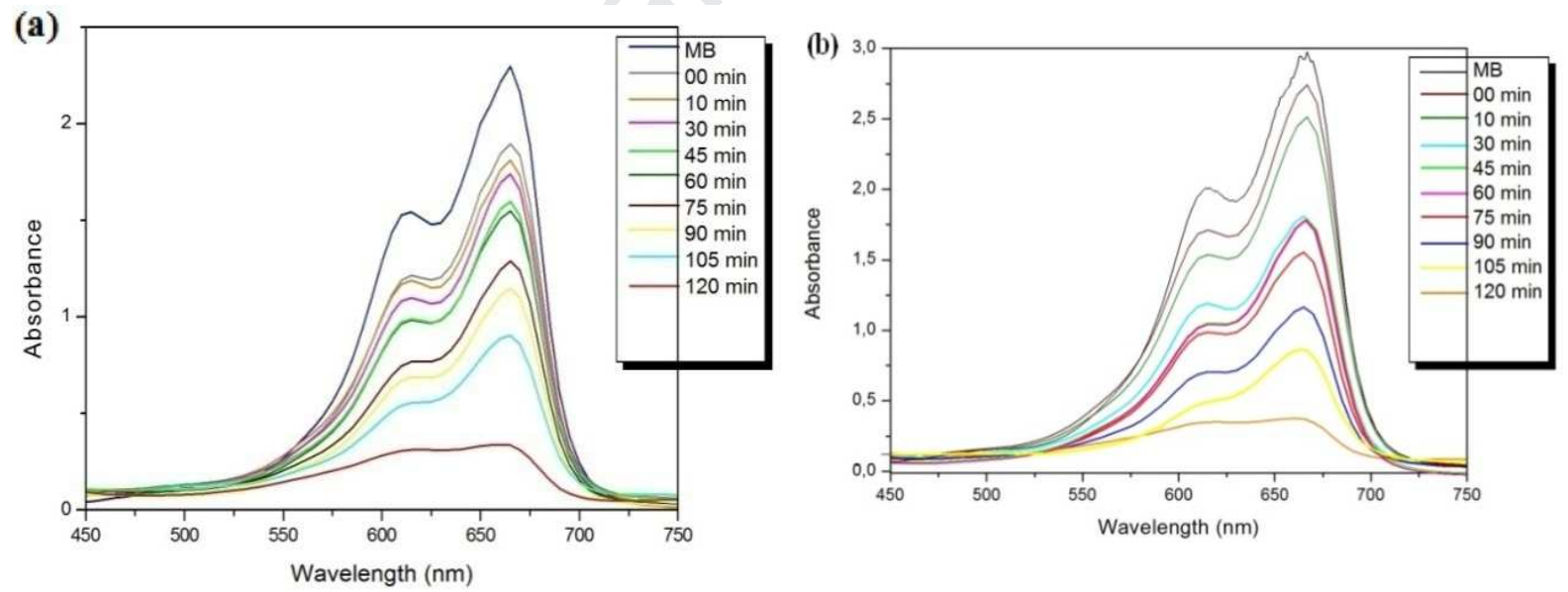

Figure 11. UV-Vis absorption spectrums of degradation of $50 \mathrm{ml} \mathrm{MB}$ aqueous solution under a sunlight radiation in presence of $20 \mathrm{mg}$ of (1) (a) and $20 \mathrm{mg}$ of (2) (b) 


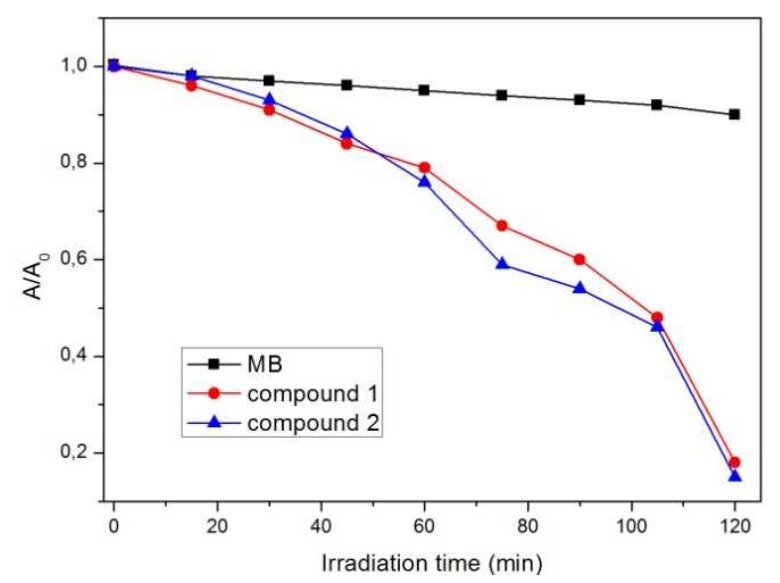

Figure 12. Plots of $\mathrm{A} / \mathrm{A}_{0}$ against reaction time of complexe (1) and complexe (2)

In order to understand the photocatalytic degradation of MB with complexes (1) and (2), a possible mechanism is proposed as follows, upon irradiation under sunlight complexes can be excited to produce light-induced electrons. These electrons are excited rapidly from the valence band $(\mathrm{VB})$ to the conduction band $(\mathrm{CB})$ at the photocatalytic surface yielding the same amount of holes $\left(\mathrm{h}^{+}\right)$in the (VB.)

Therefore, the photogenerated electrons reduce $\left(\mathrm{O}_{2}\right)$ to $\left(\mathrm{O}_{2}{ }^{-}\right)$active species, which in turn interact with water to generate hydroxyl radical $(\cdot \mathrm{OH})$. As we all know, the $(\cdot \mathrm{OH})$ radical works as a strong oxidizing agent to decompose MB into nonpolluting simple molecules and complete the photocatalytic process [36]. The main pathways of photocatalytic degradation of MB under sunlight irradiation are as follows:

$$
\begin{aligned}
& \mathrm{H}_{2} \mathrm{O} \rightarrow \mathrm{H}^{+}+\mathrm{OH}^{-} \\
& \mathrm{h}^{+}+\mathrm{OH}^{-} \rightarrow \mathrm{OH}^{-} \\
& \mathrm{e}^{-}+\mathrm{O}_{2} \rightarrow \mathrm{O}^{-} \\
& \mathrm{O}^{-}+\mathrm{H}^{+} \rightarrow \mathrm{HO}_{2} \\
& 2 \mathrm{HO}_{2} \rightarrow \mathrm{H}_{2} \mathrm{O}_{2}+\mathrm{O}_{2} \\
& \mathrm{H}_{2} \mathrm{O}_{2}+\mathrm{O}_{2}^{-} \rightarrow \mathrm{OH}+\mathrm{OH}^{-}+\mathrm{O}_{2}(6) \\
& \mathrm{H}_{2} \mathrm{O}_{2}+\mathrm{hv} \rightarrow 2 \mathrm{OH}
\end{aligned}
$$




\subsection{Magnetic properties}

The magnetic properties of (1) under the form of $\chi_{M}$ and $\chi_{M} T$ versus $T\left[\chi_{M}\right.$ being the magnetic susceptibility per chromium(III) ion] are presented in Figure 13 in the temperature range 1.88$300 \mathrm{~K}$. The value of $\chi_{M} T$ at room temperature is $1.870 \mathrm{~cm}^{3} \mathrm{~mol}^{-1} \mathrm{~K}$, which is as expected for a magnetically isolated chromium(III) ion $\left(1.875 \mathrm{~cm}^{3} \mathrm{~mol}^{-1} \mathrm{~K}\right.$ for $\mathrm{S}=3 / 2$ with $\left.\mathrm{g}=2.0\right)$.

With a lowering of a temperature, the $\chi_{\mathrm{m}} T$ value decrease to reach at $1.88 \mathrm{~K}$ a value of 1.331 $\mathrm{cm}^{3} \mathrm{~mol}^{-1} \mathrm{~K}$. This decrease may be attributed to weak antiferromagnetic intermolecular interactions $(\theta)$ of six-coordinated chromium(III) ions, to the zero field splitting (D) of the chromium(III) or to both factors simultaneously.

In the light of mononuclear nature of complex (1), we have analyzed the magnetic data through the expression [equation (1)] [37]

$\chi_{\mathrm{M}}=\mathrm{N} \beta^{2} \mathrm{~g}^{2}\left(\chi_{\|}+2 \chi \perp\right) / 3 \mathrm{k} T$

where

$\chi \perp=\{4+(3 \mathrm{kT} / \mathrm{D})[1-\exp (-2 \mathrm{D} / \mathrm{k} T)]\} / 4[1+2 \exp (-2 \mathrm{D} / \mathrm{k} T)]$

and

$\chi_{\|}=[1+9 \exp (-2 \mathrm{D} / \mathrm{k} T)] / 4[1+\exp (-2 \mathrm{D} / \mathrm{k} T)]$

the Hamiltonian used being defined by equation (4)

$\mathrm{H}=\mathrm{D}\left[S_{z}^{2}-1 / 3 \mathrm{~S}(\mathrm{~S}+1)\right]$

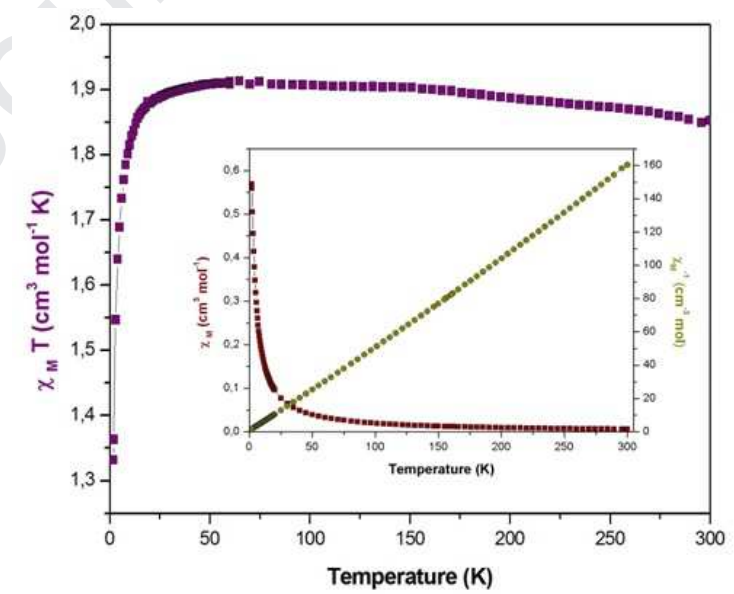

Figure 13. Plots of the temperature dependence of $\chi_{M}$ and $\chi_{M} T$ for $\operatorname{Cr}(\mathrm{III})$ complex (1)

The parameters $\mathrm{N}, \beta, \mathrm{k}$ and $\mathrm{g}$ in equation (1) have their usual meanings. Least-squares fit of the $\chi_{\mathrm{M}} T$ data through equation (1) leads to the following set of parameters: $\mathrm{D}=4.35 \mathrm{~cm}^{-1}$, $\mathrm{g}=1.98$ and $\mathrm{R}=1.42 .10^{-4}\left(\mathrm{R}\right.$ is the agreement factor defined as $\sum i\left[\left(\chi_{\mathrm{M}} T\right)_{\mathrm{obs}}(\mathrm{i})\right.$ $\left.\left.\left(\chi_{\mathrm{M}} T\right)_{\text {calc }}(\mathrm{i})\right]^{2} / \sum i\left[\left(\chi_{\mathrm{M}} T\right)_{\mathrm{obs}}(\mathrm{i})\right]^{2}\right)$. The agreement with the calculated and theoretical data was no 
quite good. Assuming that the decrease of the susceptibility data of (1) is only due to intermolecular interactions ( $\theta), \mathrm{D}$ is made equal to zero in eqns. (1), (2) and (3) and T was replaced by $\mathrm{T}-\theta$ in eqn. (1). Least-squares fit through the modified expression of eqn. (1), leads to parameter $\theta$ equal to $-0.82 \mathrm{~K}$ and $\mathrm{g}$ value equal to 1.98 and $\mathrm{R}=4.10^{-5}$. The computed curve didn't follow the magnetic data better than the first fit. Finally, we have tried to simulate the magnetic data through Eq. (1). by replacing $\mathrm{T}$ by $\mathrm{T}-\theta$ and taking into account $\mathrm{D}$ as a variable parameter in eqns. (2) and (3). Best-fit parameters for this case are $\mathrm{D}=1 \mathrm{~cm}^{-1}, \mathrm{~g}=$ $1.98, \theta=-0.68 \mathrm{~K}$ and $\mathrm{R}=8.410^{-6}$. The computed curve match the magnetic data very well in this case (Figure $\mathrm{S} 3$ ).

Thus, we have only considered the third fit results and we have concluded that the decrease of the values of $\chi_{\mathrm{M}} T$ is due to the existence of a weak antiferromagnetic interaction between the $\left[\mathrm{Cr}\left(\mathrm{C}_{2} \mathrm{O}_{4}\right)_{2}\left(\mathrm{H}_{2} \mathrm{O}\right)_{2}\right]^{-}$entities with a little contribution of ZFS effect.

In fact, the small magnetic coupling observed in complex (1) is in agreement with the mononuclear nature and the large intermolecular metal-metal separation (Cr...Cr being equal to $6.089 \AA$ ) across the possible long exchange pathways within the supramolecular system .

\section{Conclusion}

In summary, two chromium coordination compounds with different structures have been obtained by slow evaporation of the solvent reactions at room temperature. The two coordination compounds extend into 3-D supramolecular architectures by hydrogen bonding interactions and/or $\pi-\pi$ stacking interactions. Structural analyses revealed differences in their formulations and in their supramolecular connectivity.

The results of thermal analysis was performed to show the good agreement with the molecular formula and to prove the thermal stability of the compound. All the existing spin-allowed transitions presented in the electronic absorption spectra have been assigned using TanabeSugano diagram. Racah parameters were calculated to evaluate the nephelauxetic effect of $\left(\mathrm{Cr}^{3+}\right)$. The Tauc model was used to obtain the optical band gap and the obtained values have permitted to classify them as semi-conductors.

Moreover, the photocatalytic experiments showed that both complexes are good candidates for the photocatalytic degradation of methylene blue. The results of this study may be helpful in facilitating the design of new photocatalytic materials. The variable temperature magnetic susceptibility measurement of compound (1) shows the existence of weak antiferromagnetic interactions between the metal centers. 


\section{Supplementary materials}

Crystallographic data and full lists of bond lengths and angles have been deposited with the Cambridge Crystallographic Data Centre, CCDC No 1582710 for compound (1) and 1582711 for compound (2). Copies of this information may be obtained free of charge from The Director, CCDC, 12 Union Road, CAMBRIDGE, CB2 1EZ, UK (fax:+44-1223-336-033; e mail:deposit@ccdc.cam.ac.uk or http://www.ccdc.cam.ac.uk).

\section{References}

[1] S. H. Mir, L. A. Nagahara, T. Thundat, P. Mokarian-Tabari, H. Furukawa, A. Khosla, Organic-Inorganic Hybrid Functional Materials: An Integrated Platform for Applied Technologies, J. Electrochem. Soc., 165 (2018) 3137-3156. doi: 10.1149/2.0191808jes.

[2] Y. Xie, H. Yang, Z. U. Wang, Y. Liu, H. C. Zhou, J. R. Li, Unusual preservation of polyhedral molecular building units in a metal-organic framework with evident desymmetrization in ligand design, Chem. Commun., 5 (2014) 563-565. doi: 10.1039/C3CC48089E.

[3] C. Wang, G. Guo, P. Wang, Two sodium and lanthanide(III) MOFs based on oxalate and V-shaped 4,4'-oxybis(benzoate) ligands: Hydrothermal synthesis, crystal structure, and luminescence properties, J. Mol. Struc., 1032 (2013) 93-99. doi: 10.1016/j.molstruc.2012.07.039. [4] X. Dui, W. Yang, X. Wu, X. Kuang, J. Liao, R. Yu, and C. Lu, Two novel POM-based inorganic-organic hybrid compounds: synthesis, structures, magnetic properties, photodegradation and selective absorption of organic dyes, Dalton Trans., 20 (2015) 94969505. doi: 10.1039/c5dt01042j.

[5] C. Gong, X. Zeng, C. Zhu, J. Shu, P. Xiao, H. Xu, L. Liu, J. Zhang, Q. Zeng, J. Xie, A series of organic-inorganic hybrid materials consisting of flexible organic amine modified polyoxomolybdates: synthesis, structures and properties, RSC Adv., 6 (2016) 106248-106259. doi: 10.1039/C6RA21603J.

[6] C.C.Wang, J.R. Li, X.L. Lv, Y.Q. Zhang, G. Guo, Photocatalytic organic pollutants degradation in metal-organic frameworks, Energ. Environ. Sci., 7 (2014) 2831-2867. doi: 10.1039/C4EE01299B.

[7] M. A. Hassaan, A. El Nemr, Health and Environmental Impacts of Dyes, Am. J. of Env. Sci. Eng., 3 (2017) 64-67. doi: 10.11648/j.ajese.20170103.11. 
[8] O. Kahn, C.J. Martinez, From Molecular Materials Toward Memory Devices, Science., 279 (1998) 44-48. doi: 10.1126/science.279.5347.44.

[9] S. Hill, R.S. Edwards, N. Aliaga-Alcalde, G. Christou, Quantum Coherence in an Exchange-Coupled Dimer of Single-Molecule Magnets, Science., 302 (2003) 1015-1018. doi: 10.1126/science. 1090082 .

[10] K. Xiong, F. Jiang F, M. Yang, M. Wu, R. Feng, W. Xu, M. Hong, 2D Sheet-like architectures constructed from main-group metal ions, 4,4'-bpno and 1,2-alternate $p$ sulfonatothiacalix[4]arene, Dalton Trans., 41 (2012) 540-545. doi: 10.1039/C1DT11239B.

[11] S. Benmansour, F. Setifi, S. Triki, C. J. Gomez-Garcia, Linkage Isomerism in Coordination Polymers, Inorg. Chem., 51 (2012) 2359-2365. doi: 10.1021/ic202361p.

[12] S. Noro, R. Kitaura, M. Kondo, S. Kitagawa, T. Ishii, H. Matsuzaka, MJ. Yamashita, Framework Engineering by Anions and Porous Functionalities of $\mathrm{Cu}(\mathrm{II}) / 4,4^{4}$-bpy Coordination Polymers, Am. Chem. Soc., 124 (2002) 2568-2638. doi: 10.1021/ja0113192.

[13] I. Muga, J. M. Gutierrez-Zorrilla, P. Vitoria, P. Roman, F. Lloret, Binuclear Ni(II) complexes based on bridging oxalate and tetracyanometallates, Polyhedron., 21 (2002) 26312638. doi: 10.1016/S0277-5387(02)01240-8.

[14] F. Tuna, G.I. Pascu, J.P. Sutter, M. Andruh, S. Golhen, J. Guillevic, H. Pritzkow, Synthesis, crystal structures and magnetic properties of new oxalato- and phenolato-bridged binuclear copper(II) complexes with Schiff-base ligands, Inorg. Chim. Acta., 342 (2003) 131138. doi: 10.1016/S0020-1693(02)01155-6.

[15] K. Li, L. Luo, J. Huang, X. Ma, H. Wang, Y. Feng, X. Liu, The evolution of structure and properties for copolyamide fibers-containing benzimidazole units during the decomplexation of hydrogen chloride, High perform. polym., 28 (2016) 381-389. doi: $10.1177 / 0954008315583704$.

[16] G. A. Timco, E. J. L. McInnes, R. E. P. Winpenny, Physical studies of Heterometallic Rings: An Ideal System for Studying Magnetically-coupled Systems, Chem. Soc. Rev., 42 (2013) 1796-1806. doi: 10.1039/c2cs35232j.

[17] P. J. Alonso, A. B. Arauzo, M. A. Garcia-Monforte, I. GarciaRubio, A. Martin, B. Menjon, C. Rillo, Synthesis, Characterisation and Magnetic Properties of Octahedral Chromium(III) Compounds with Six C-donor Ligands, Dalton Trans., 40(2011) 853-861. doi: 10.1039/c0dt00891e. 
[18 ] P.Cieśla, P. Mytych, P.Kocot, Z. Stasicka, Role of Iron and Chromium Complexes in Environmental Self-cleaning Processes, Sep. Sci. Technol., $42: 7$ (2007) 1651-1666. doi: 10.1080/01496390701290540.

[19] G.M. Sheldrick (1997) SHELXS-97, Programs for Solution of Crystal Structure, University of Göttingen, Germany.

[20] G.M. Sheldrick (2014) SHELXL 2014/1 Programs for the Solution and Refinement of Crystal Structures; University of Göttingen: Göttingen, Germany.

[21] K. Brandenburg (2003) Visual crystal structure information system, Version 3.0, University of Bonn, Germany.

[22] M. Marchivie, P. Guionneau, J.F. Leatard, D. Chasseau, Towards direct correlations between spin-crossover and structural features in iron(II) complexes, Acta Crystallogr. Sect. B: Struct. Sci., 59 (2003) 479-486. doi: 10.1107/S0108768103011200.

[23] M. M. Belombe, J. Nenwa, F. Emmerling, Crystal structure of quinolinium transdiaquabis(oxalato-O,O')- chromate(III), Z. Kristallogr. New Cryst. Struct., 224 (2009) 239240. doi: 10.1524/ncrs.2009.224.14.249.

[24] V. Kahlenberg, W. Wertl, D. M. Többens, H. Schottenberger, Structural Investigations and Thermal Behavior of $(E M I m)\left[C r\left(\mathrm{C}_{2} \mathrm{O}_{4}\right)_{2}\right] \cdot 2 \mathrm{H}_{2} \mathrm{O}$ [1-Ethyl-3-methylimidazolium Chromium(III) Dioxalate Dihydrate], Z. Anorg. Allg. Chem., 637 (2011) 1371-1377. doi: 10.1002/zaac.201100109.

[25] J. Bernstein, R. E. Davis, L. Shimoni, N. L. Chang, Patterns in hydrogen bonding: functionality and graph set analysis in crystals, Angew. Chem. Int. ED. Engl., 34 (1995) 15551573. doi: 10.1002/anie.199515551

[26] M. Amudha, P. Praveen Kumar, G. Chakkaravarthi, Benzimidazolium L-aspartate, Acta Crystallogr. Sect. E., 1 (2016) 1-7. doi: 10.1107/S2414314616006775.

[27] M.Amudha, P. Praveen Kumar, G. Chakkaravarthi, Crystal structure of benzimidazolium salicylate, Acta Crystallogr. Sect. E., 71 (2015) 794-795. doi: 10.1107/S2056989015017764. [28] E. Coronado, J. R. Galan-Mascaros, C. Marti-Gastaldo, Design of bimetallic magnetic chains based on oxalate complexes: towards single chain magnets, Cryst Eng Comm., 11 (2009) 2143-2153. doi: 10.1039/B910490A.

[29] L. Martin, A. Christian, H. Akutsu, Tricaesium tris(oxalato- $\left.\mathrm{k}^{2} \mathrm{O}^{1}, \mathrm{O}^{2}\right)$ - chromate(III) dihydrate, Acta Crystallogr. Sect. C., 66 (2010) 157-159. doi: 10.1107/S0108270110014861. [30] C. Gabriel, C. P. Raptopoulou, A. Terzis, N. Lalioti, A. Salifoglou, Synthesis, structural, spectroscopic and magnetic susceptibility studies of a soluble $\mathrm{Cr}$ (III)-heida (2- 
hydroxyethyliminodiacetic acid) complex. Relevance to aqueous chromium(III)-heida speciation, Inorg. Chim. Acta., 360 (2007) 513-522. doi: 10.1016/j.ica.2006.07.097.

[31] L. Vijayalakshmi, V. Naresh, R. Ramaraghavulu, B.H. Rudramadevi, S. Buddhudu, Preparation and Characterization of $\mathrm{Ti}^{3+} \& \mathrm{Cr}^{3+}: \mathrm{Li}_{2} \mathrm{O}-\mathrm{LiF}_{-} \mathrm{B}_{2} \mathrm{O}_{3^{-}} \mathrm{ZnO}$ Optical Glasses, Int $\mathrm{J}$ Eng Res Appl., 4 (2014) 168-176.

[32] A. Kumara, A. Kumara, G. Sharmaa, M. Naushadb, R. Cataluna Vesesc, A. A. Ghfarb, F. J. Stadlerd, M. Rizwan Khan, Solar-driven photodegradation of 17- $\beta$-estradiol and ciprofloxacin from waste water and $\mathrm{CO}_{2}$ conversion using sustainable coal-char/polymeric-g$\mathrm{C}_{3} \mathrm{~N}_{4} / \mathrm{RGO}$ metal-free nano-hybrids, New J. Chem., 41 (2017) 10208-10224. doi: 10.1039/C7NJ01580A.

[33] P. M. Krishna, A. N. Reddy, K. H. Reddy, Cobalt (II) complex of (3-Amino-5-[E-(4ethylbenzaldene)4- methyl-2-phenylcyclopetanone): Synthesis, characterization and photocatalytic studies, Int. J. Chem. tech. Res., 12 (2019) 171-177. doi: 10.20902/IJCTR.2019.120119.

[34] D. A. Wulandari1, A. Zulys, E. Kusrini, Samarium Complexes from 2,6Naphtalenedicarboxylate: Synthesis, Photocatalytic Properties and Degradation of Methylene Blue, Conf. Ser.: Mater. Sci. Eng., 546 (2019) 042050. doi: 10.1088/1757899X/546/4/042050.

[35] D.Z. Wang, J.P Li, J. Z. Fan, D.Z. Jia, Metal-organic coordination architectures of bis(Nimidazolyl) pyridazine: Syntheses, structures, emission and photocatalytic properties, Polyhedron, 111 (2016) 123-131. doi: 10.1016/j.poly.2016.03.025.

[36] S. Dong, J. Feng, M. Fan, Y. Pi, L. Hu, X. Han, M. Liu, J. Sun, J.Sun, Recent developments in heterogeneous photocatalytic water treatment using visible-light-responsive photocatalysts: A review, RSC Adv., 19 (2015) 14610-14630. doi: 10.1039/C4RA13734E.

[37] C. J. O'Connors, Magnetochemistry- Advances in Theory and Experimentation, Prog. Inorg. Chem., 29 (1986) 203-283. doi: 10.1002/9780470166307.ch4.

\section{Figure captions:}

Figure 1. A view of the asymmetric unit of (1) with the atom numbering scheme. Displacement ellipsoids are drawn at the $50 \%$ probability level and $\mathrm{H}$ atoms are represented as spheres of arbitrary radius

Figure 2. (a) View of a 2-D network of (1) through adjacent chains which are formed by intermolecular hydrogen bonding interactions; (b) View of 5 identifying the graph set motifs within the hydrogen bonded sheets 
Figure 3. Projection of the $\left(\mathrm{C}_{7} \mathrm{H}_{7} \mathrm{~N}_{2}\right)\left[\mathrm{Cr}\left(\mathrm{C}_{2} \mathrm{O}_{4}\right)_{2}\left(\mathrm{H}_{2} \mathrm{O}\right)_{2}\right] \cdot 2 \mathrm{H}_{2} \mathrm{O}$ structure along the $a$ axis showing the hydrogen-bonded network

Figure 4. Intermolecular O-H... O and N-H...O hydrogen bonds present in compound (1)

Figure 5. A view of the asymmetric unit of (2) with the atom numbering scheme. Displacement ellipsoids are drawn at the $50 \%$ probability level and $\mathrm{H}$ atoms are represented as spheres of arbitrary radius

Figure 6. Projection of along the $\mathrm{c}$ axis showing the hydrogen-bonded network

Figure 7. View of a fragments of the molecular structure of $\left(\mathrm{C}_{7} \mathrm{H}_{7} \mathrm{~N}_{2}\right)_{3}\left[\mathrm{Cr}\left(\mathrm{C}_{2} \mathrm{O}_{4}\right)_{3}\right]\left(\mathrm{H}_{2} \mathrm{C}_{2} \mathrm{O}_{4}\right) 3 . \mathrm{H}_{2} \mathrm{O}$ showing well-directional hydrogen bonding interactions

Figure 8. (a) View of the 3-D network of compound (2); (b) A view of the hydrogen bonding in (2), showing the ring motif

Figure 9. TGA curves of $\left(\mathrm{C}_{7} \mathrm{H}_{7} \mathrm{~N}_{2}\right)\left[\mathrm{Cr}\left(\mathrm{C}_{2} \mathrm{O}_{4}\right)_{2}\left(\mathrm{H}_{2} \mathrm{O}\right)_{2}\right] \cdot 2 \mathrm{H}_{2} \mathrm{O} \quad$ (1) (a) and $\left(\mathrm{C}_{7} \mathrm{H}_{7} \mathrm{~N}_{2}\right)_{3}\left[\mathrm{Cr}\left(\mathrm{C}_{2} \mathrm{O}_{4}\right)_{3}\right]\left(\mathrm{H}_{2} \mathrm{C}_{2} \mathrm{O}_{4}\right) \cdot 3 \mathrm{H}_{2} \mathrm{O}$ (2) (b)

Figure 10. UV-Visible of $\left(\mathrm{C}_{7} \mathrm{H}_{7} \mathrm{~N}_{2}\right)\left[\mathrm{Cr}\left(\mathrm{C}_{2} \mathrm{O}_{4}\right)_{2}\left(\mathrm{H}_{2} \mathrm{O}\right)_{2}\right] \cdot 2 \mathrm{H}_{2} \mathrm{O} \quad$ (1) (a) and

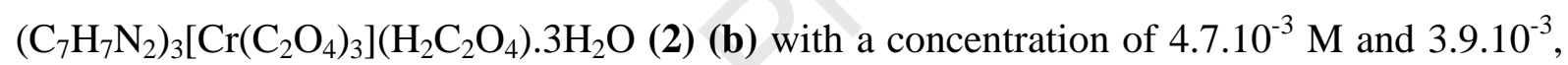
respectively, and a path length $\mathrm{d}$ of $1.0 \mathrm{~cm}$

Figure 11. UV-Vis absorption spectrums of degradation of $50 \mathrm{ml} \mathrm{MB}$ aqueous solution under a sunlight radiation in presence of $20 \mathrm{mg}$ of (1) (a) and $20 \mathrm{mg}$ of (2) (b)

Figure 12. Plots of $A / A_{0}$ against reaction time of compound (1) and compound (2)

Figure 13. Plots of the temperature dependence of $\chi_{M}$ and $\chi_{M} T$ for $\mathrm{Cr}(\mathrm{III})$ complex (1)

\section{Table captions:}

Table 1. Summary of the crystal data and structure refinement for

$\left(\mathrm{C}_{7} \mathrm{H}_{7} \mathrm{~N}_{2}\right)\left[\mathrm{Cr}\left(\mathrm{C}_{2} \mathrm{O}_{4}\right)_{2}\left(\mathrm{H}_{2} \mathrm{O}\right)_{2}\right] \cdot 2 \mathrm{H}_{2} \mathrm{O}(\mathbf{1})$ and $\left(\mathrm{C}_{7} \mathrm{H}_{7} \mathrm{~N}_{2}\right)_{3}\left[\mathrm{Cr}\left(\mathrm{C}_{2} \mathrm{O}_{4}\right)_{3}\right]\left(\mathrm{H}_{2} \mathrm{C}_{2} \mathrm{O}_{4}\right) 3 \cdot \mathrm{H}_{2} \mathrm{O}$ (2)

Table 2. Hydrogen bonds of complex (1)

Table 3. Hydrogen bonds of complex (2) 


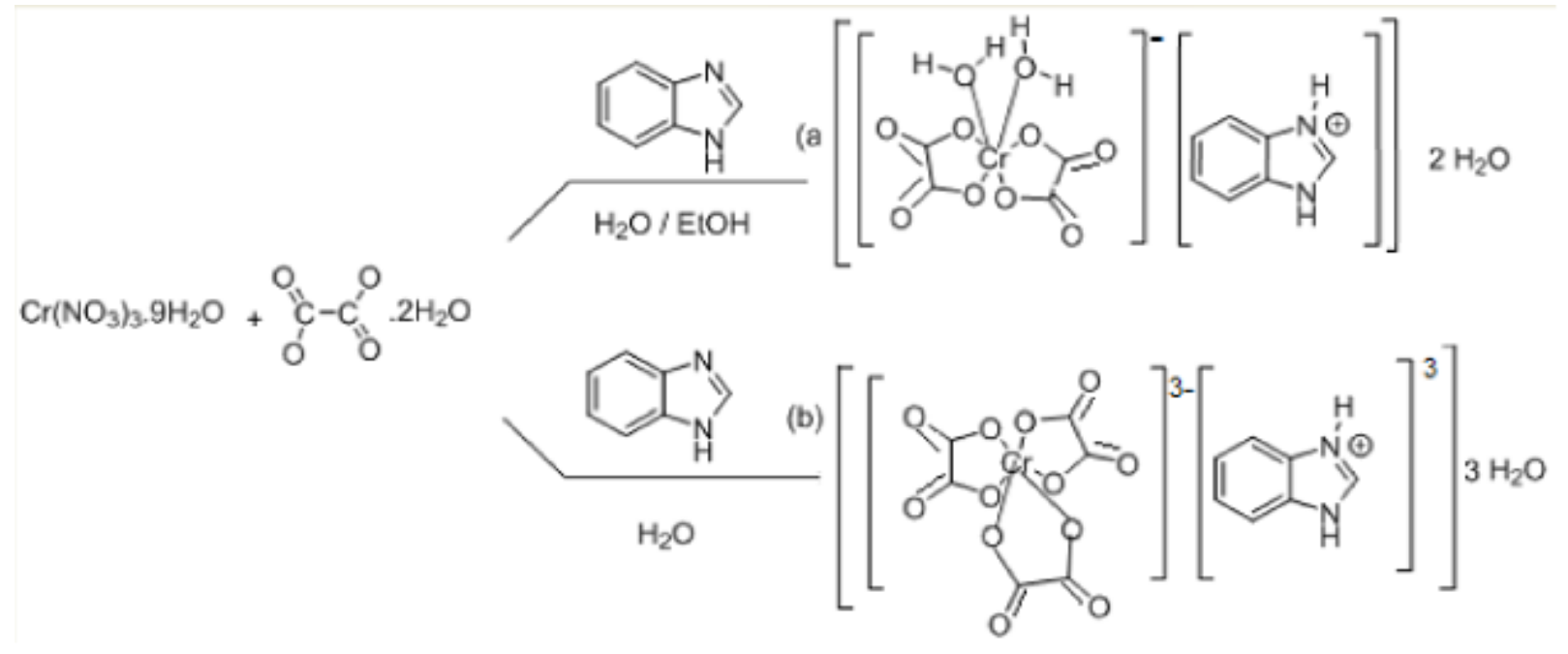




\section{HIGHLIGHTS :}

- Supramolecular chromium (III) compounds were synthesized by slow evaporation at room temperature.

- The photochemistry behavior of both compounds were investigated.

- Magnetic study shows the presence of an antiferromagnetic interaction.

- Both compounds exhibit good photocatalytic capability in degradation of MB 
Author Contributions Section

Saoussen Namouchi cherni: Conceptualization, Methodology, Software Dridi rihab.: Data curation, Writing- Original draft preparation. Fettar ferid : Visualization, Investigation. Zid Mohamed faouzi: Supervision.: Nassira Chniba-Boudjada: Software, Validation. 
Declaration of interests

$\checkmark \quad$ The authors declare that they have no known competing financial interests or personal relationships that could have appeared to influence the work reported in this paper. 